\title{
Experimental Investigation on Corrosion of Cast Iron Pipes
}

\author{
H. Mohebbi and C. Q. Li \\ School of Engineering, University of Greenwich, Medway ME4 4TB, UK \\ Correspondence should be addressed to C. Q. Li, c.q.li@greenwich.ac.uk
}

Received 1 December 2010; Accepted 15 March 2011

Academic Editor: Flavio Deflorian

Copyright ( $) 2011$ H. Mohebbi and C. Q. Li. This is an open access article distributed under the Creative Commons Attribution License, which permits unrestricted use, distribution, and reproduction in any medium, provided the original work is properly cited.

\begin{abstract}
It is well known that corrosion is the predominant mechanism for the deterioration of cast iron pipes, leading to the reduction of pipe capacity and ultimate collapse of the pipes. In order to assess the remaining service life of corroded cast iron pipes, it is imperative to understand the mechanisms of corrosion over a long term and to develop models for pipe deterioration. Although many studies have been carried out to determine the corrosion behavior of cast iron, little research has been undertaken to understand how cast iron pipes behave over a longer time scale than hours, days, or weeks. The present paper intends to fill the gap regarding the long-term corrosion behaviour of cast iron pipes in the absence of historical data. In this paper, a comprehensive experimental program is presented in which the corrosion behaviour of three exservice pipes was thoroughly examined in three simulated service environments. It has been found in the paper that localised corrosion is the primary form of corrosion of cast iron water pipes. It has also been found that the microstructure of cast irons is a key factor that affects the corrosion behaviour of cast iron pipes. The paper concludes that long-term tests on corrosion behaviour of cast iron pipes can help develop models for corrosion-induced deterioration of the pipes for use in predicting the remaining service life of the pipes.
\end{abstract}

\section{Introduction}

Cast iron has been used extensively in many industrial applications, such as water industry, for more than 150 years. As a result, a large proportion of water transport and distribution pipes were predominantly made of cast iron in the past although they are being phased out by the introduction of new materials. Buried cast iron pipes age and deteriorate during the service due to various aggressive environments surrounding the pipes. Depending on a variety of factors, including the type of cast iron materials, local geology, and operation conditions, cast iron pipes deteriorate at different rate $[1,2]$. The problem can be further complicated by the diversity in production quality in both cast iron material and pipes and the wide range in the diameter and wall thickness of the pipes. To ensure the safety and reliability of cast iron pipes in service, maintenance and targeted replacement for the deteriorated pipes are necessary. To develop a costeffective and risk-informed maintenance or replacement strategy, it is imperative to understand the mechanisms of pipe deterioration and, based on this understanding, to develop a model for the prediction of the deterioration so that it can be used by engineers and asset managers as a tool for asset management of cast iron pipes.

It has been well known that corrosion is the predominant mechanism for the deterioration of cast iron pipes [2-5], leading to the reduction of pipe capacity and ultimately the collapse of the pipes. Of various forms of corrosion, corrosion pits in particular can act as foci to stresses imposed to a pipe $[3,4]$, which accelerate pipe deterioration and subsequent failures. Hence, any information on the factors controlling and influencing the rate at which these corrosion pits initiate and infiltrate to pipes is of particular importance. Moreover, in order to better model corrosioninduced deterioration and importantly its contribution to pipe failures, a thorough understanding of the corrosion behavior of cast iron pipes is essential.

Many studies have been carried out to determine the corrosion behavior of cast iron in aqueous environment of various degrees of corrosiveness [6-10]. Most of these studies have been results of works within a time frame of hours, days, weeks, and in very limited cases months, and not much 
literature can be found on a long-term corrosion study, such as years. Literature $[6,7]$ measured the electrochemical parameters of cast iron specimens using DC polarization technique. With the understanding of the importance of the medium and the exposure period on the corrosion behavior of the specimens, they calculated the corrosion rate of the specimens in different test solutions for the exposure period of $1,3,5,8$, and 15 days. Such short-term studies can be used to support the investigation of the fracture surface of a failed pipe by providing a link between time of exposure and the observed extent of corrosion. Literature $[8,9]$ measured the corrosion properties of cast iron specimens when exposed in mildly alkaline test solutions for 124 days. Clearly, 124-day exposure time will not account for the long term corrosion behavior of the specimens. In contrast, some studies have focused on pipes that have been aged in service and investigated the effect of corrosion and corrosion pits $[2,11]$. In the case of buried cast iron pipes, it is common to assess the condition of pipes based on an estimation of the corrosion rate from pipes age, which in most cases is unknown. A literature survey (see references) suggests that little research has been undertaken to understand how cast iron pipes behave in a range of service environments over a longer time scale than hours, days or weeks.

The intention of this paper is to investigate the corrosion behaviour of cast iron pipes in a relatively long term. A comprehensive experimental program is presented in which the corrosion of three exservice pipes was thoroughly examined in three simulated service environments using various corrosion techniques. The experiment was set up in three sets running parallel to each other, each resembling the service environments in which pipes were laid with the outside-in corrosion of the pipe. From the experiment and its results, the morphology of corrosion products of cast iron pipes was investigated and the corrosion rate determined. Also in the paper, the long-term corrosion properties of cast iron pipes were characterised. The paper attempts to fill the gap regarding the long-term corrosion behaviour of cast iron pipes in the absence of historical data.

\section{Test Specimens}

Specimens were sourced from three exservice water mains, denoted as Pipes 1, 2, and 3. Three large plates (approximately $450 \mathrm{~mm}$ by $450 \mathrm{~mm}$ ) were taken from each pipe, and test specimens were cut from these plates to the nominal size of $35 \times 25 \mathrm{~mm}$ of the thickness of the plates. Figure 1 shows the rectangular bars cut from these three plates and various extent of graphitisation on the bars. As can be seen, the as-received pipes display a range of corrosion conditions with a mixture of general and more localised corrosion being evident on both the external and internal surfaces of the plates. More details regarding the dimension, thickness of the pipes, and the plates cut from these pipes can be found in a previous study [12].

Information regarding the extent of these corrosion pits is presented in Table 1. General corrosion in this case is considered to be where the depth of corrosion is relatively
TABLE 1: Information on pipes and corrosion.

\begin{tabular}{lcccc}
\hline Pipe & $\begin{array}{c}\text { Thickness of pipe } \\
(\mathrm{mm})\end{array}$ & $\begin{array}{c}\text { Pit depth } \\
(\mathrm{mm})\end{array}$ & $\begin{array}{c}\text { Pit width } \\
(\mathrm{mm})\end{array}$ & $\begin{array}{c}\text { Approximate } \\
\text { age (year) }\end{array}$ \\
\hline 1 & $35.9 \pm 1.6$ & $\begin{array}{c}1.625 \pm \\
0.51\end{array}$ & $45 \pm 34$ & 90 \\
2 & $35.8 \pm 0.8$ & $\begin{array}{c}2.625 \pm \\
0.47\end{array}$ & $13 \pm 1.8$ & 90 \\
3 & $22.5 \pm 0.8$ & $9.1 \pm 1.24$ & $\begin{array}{c}117.2 \pm \\
18.2\end{array}$ & 90 \\
\hline
\end{tabular}

uniform over the width of the specimen, whilst localised corrosion is characterised by a region of penetrating corrosion that occurs within adjacent regions of almost unaffected material. In some cases, it is apparent that these two types are intermixed. Pipes 1 and 2 (Figures 1(a) and 1(b)) are characterised by quite limited general corrosion whilst Pipe 3 (Figure $1(\mathrm{c})$ ) is more degraded and shows mainly the presence of localised corrosion.

To study the corrosion of cast iron, it is important to know its microstructure. Figure 2 shows the photomicrographs of the morphology of microstructure taken for Pipes 1-3. As can be seen, Figure 2(a) shows a type B "rosette" graphite morphology observed at Pipe 3 with details in Figure 2(b), Figure 2(c) shows a type A "scythe/sickle" graphite morphology observed at Pipe 2 with details in Figure 2(d), and Figure 2(c) shows a mixture of type A and type B graphite morphology observed at Pipe 1 with details in Figure 2(f).

From Figure 2, it can be seen that images taken by optical microscopy reveal differences in the microstructure of the specimens taken from different pipes. The microstructures of all the pipes show a multiphase matrix of pearlite, ferrite, and phosphide eutectic with different graphite morphology. A summary regarding the graphite morphology, with reference to ASTM A247-98, is presented in Table 2. The chemical composition of the cast iron was determined using energy dispersive X-ray spectroscopy (EDX) and is given along with the percentages of the phases present in the microstructure in Table 3.

\section{Testing Methodology}

3.1. Test Setup and Techniques Used. The specimens cut from exservice pipe plates were washed using 50\% acetone, dried, and weighed prior to the exposure to the test environment. The experiment was set up in three sets running parallel to each other, each resembling the service environments in which pipes were laid with the outside-in corrosion of the pipe. The first set of experiment was the scenario where pipes were exposed to static water. The second and third scenarios represented the condition when pipes were laid in aerated and corrosive environment, respectively, and constantly being washed by flowing water (aerated). Eight specimens from each pipe were used for aerated and three specimens for static experiment. The specimens were placed on knife edge nylon bars in three different treys, one filled with tap water and the other two exposed to flowing water 


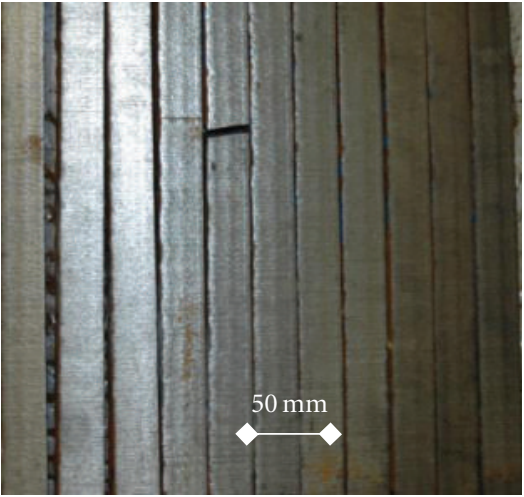

(a)

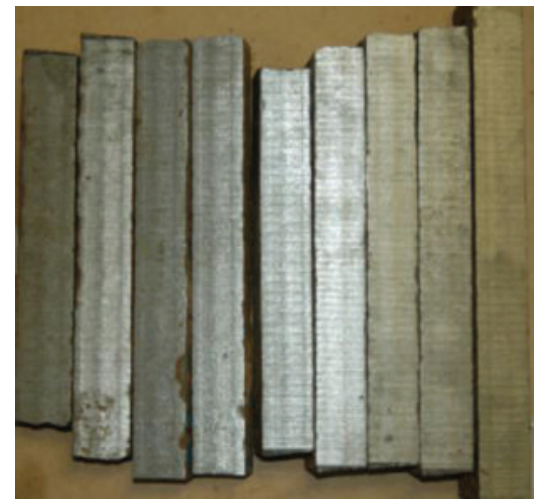

(b)

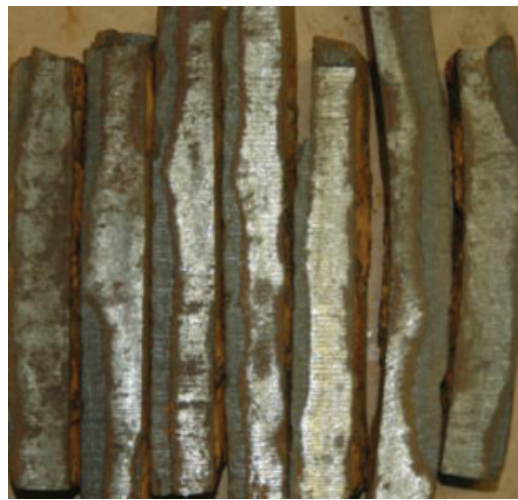

(c)

Figure 1: Test specimens cut from (a) Pipe 1, (b) Pipe 2, and (c) Pipe 3.

TABLE 2: Graphite flake identification.

\begin{tabular}{ccccccccc}
\hline \multirow{2}{*}{$\begin{array}{c}\text { Pipe } \\
\end{array}$} & \multicolumn{3}{c}{ The edges } & \multicolumn{3}{c}{ The mid section } \\
& Form & Type & Size class & Maximum flake size/mm & Form & Type & Size class & Maximum flake size/mm \\
\hline 1 & VII & Between A and B & 3 & 0.3 & VII & Between A and B & 2 & 0.45 \\
2 & VII & A & 2 & 0.4 & VII & A & 1 & 0.9 \\
3 & VII & B & 2 & 0.4 & VII & B & 2 & 0.4 \\
\hline
\end{tabular}

Note. A is "Random orientation" and B is "Rosette" graphite morphology.

pumped from two reservoir tanks, one containing tap water and the other salt water. For static experiment, 15 litres of solution in the tank was employed while, for aerated experiment, 25 litres (volume of flowing water on the tray plus volume of the water in the tank). For the flowing water environment, water was pumped from a 10-litre reservoir tank with a flow rate of $0.3 \mathrm{~mm}^{3} / \mathrm{s}$ using MULTI 1300 Water Feature pump from the supplier Pump Express. Figure 3 shows the general arrangement used to expose the specimens to the different test solutions used in this study.

To be able to obtain an overview of true corrosion behaviour, it is useful to employ a number of techniques and extract the relevant information obtained from each. Hence, in this paper, observations on the overall corrosion behaviour of the pipes have been obtained by considering the contribution of each technique. For this, three lines of studies have been conducted. First was the study of the morphology of the corrosion products. This includes the study of the appearance of the corrosion products formed on the surface of the specimens as well as the depth and form of the corrosion that developed in the specimen. Metallurgical examination for the microstructure of the specimens was carried out using methods established in a previous study [13], for example, optical microscopy and SEM (scanning electron microscopy). Following this, the electrochemical aspects and properties of corrosion were measured employing different techniques, such as DC polarisation and electrochemical frequency modulation (EFM). Finally, the corrosion products formed on the surface of the specimen were identified and analysed using such techniques as X-ray photon spectroscopy (XPS) and X-ray diffraction (XRD).
3.2. Electrochemical Measurement. Electrochemical measurements were carried out one year after commencement of the test using a Gamry PCI 4750 potentiostat. Starting from six month after the commencement of the test, the open circuit potential was monitored and recorded in 30day interval. At the end of one year period of exposure, the polarisation curve of the samples was obtained. A saturated calomel electrode and a carbon rod were used for reference and auxiliary electrodes, respectively. The experiment was conducted in a temperature-controlled environment at $23 \pm$ $1{ }^{\circ} \mathrm{C}$.

DC polarisation resistance and Tafel plot data were obtained for all test specimens using a Gamry framework version 5.5 and analysed by a Gamry Echem Analyst version 5.5. Each specimen was first subjected to a DC polarisation resistance with a scan rate of $0.25 \mathrm{mV} / \mathrm{S}$ on an approximately $15 \mathrm{mV}$ potential range. When the open circuit potential stabilised, Tafel plot of each individual specimen was obtained by subjecting them to cathodic and anodic polarisation with the scan rate of $0.5 \mathrm{mV} / \mathrm{S}$ on a range of $200 \mathrm{mV}$ potential. The corrosion rate, CR, of the specimens is calculated by $[14,15]$

$$
\mathrm{CR}=\frac{\left(I_{\text {Cor }}\right) M}{\rho Z F}(\mathrm{~mm} / \text { year }),
$$

where $M$ is molar weight of iron, $\rho$ is the density of iron $\mathrm{g} / \mathrm{cm}^{3}, Z$ is the number of electron involved in the reaction, $F$ is the Faraday number, and $I_{\text {Cor }}$ is corrosion current in amperes which is given by

$$
I_{\text {Cor }}=\frac{\left(\beta_{a}\right)\left(\beta_{c}\right)}{2.3\left(R_{P}\right)\left(\beta_{a}+\beta_{c}\right)},
$$


TABLE 3: Chemical composition of cast iron.

\begin{tabular}{lccccccccccc}
\hline Pipe & C & Si & P & S & Mn & V & Mo & Graphite $(\%)$ & Pearlite $(\%)$ & Ferrite $(\%)$ & Cementite $(\%)$ \\
\hline 1 & 3.23 & 2.7 & 0.60 & 0.12 & 0.60 & 0.08 & & 17 & 50 & 25 & 8 \\
2 & 2.75 & 2.35 & 1.20 & 0.08 & 0.50 & 0.10 & & 18 & 25 & 47 & 10 \\
3 & 3.20 & 2.36 & 0.30 & 0.20 & 0.70 & 0.05 & 0.01 & 13 & 70 & 10 & 7 \\
\hline
\end{tabular}

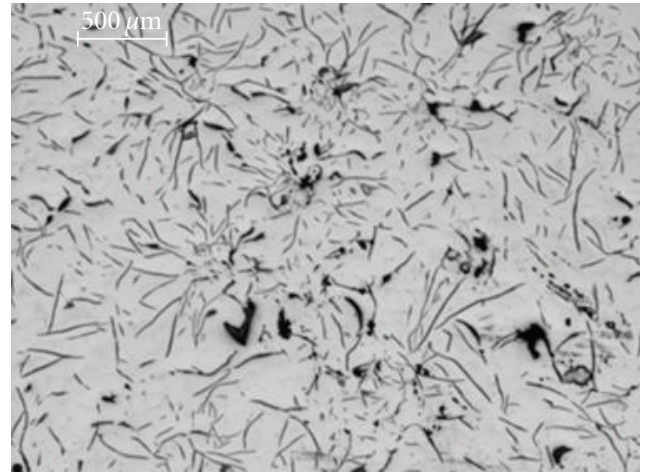

(a)

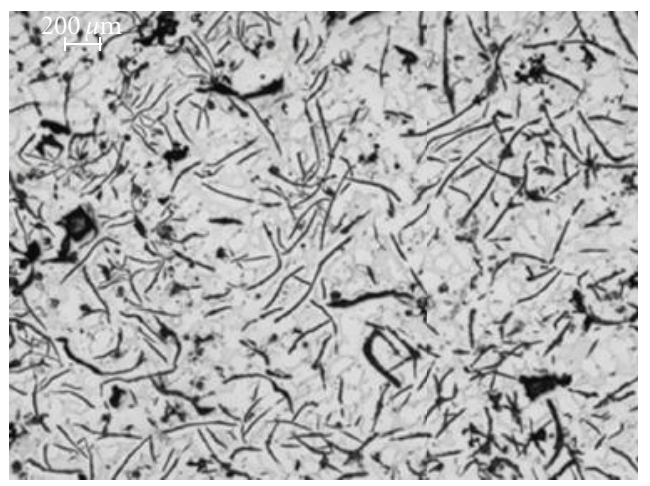

(c)

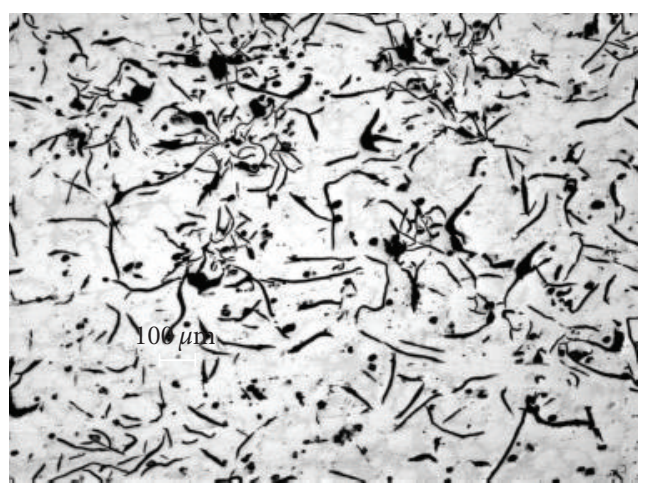

(e)

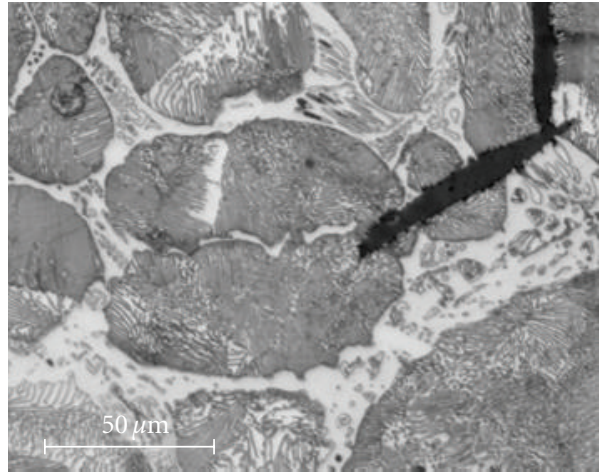

(b)

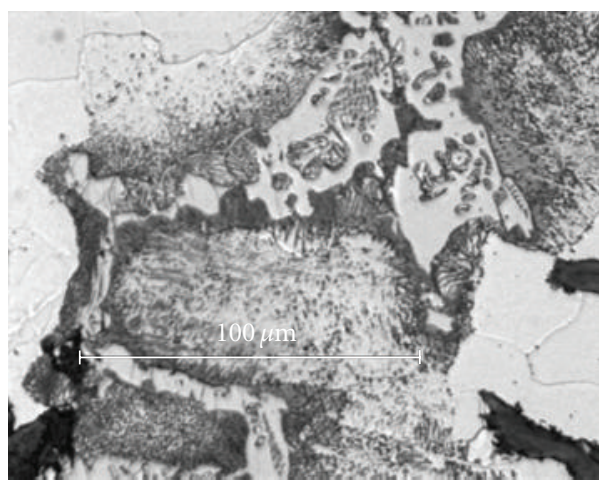

(d)

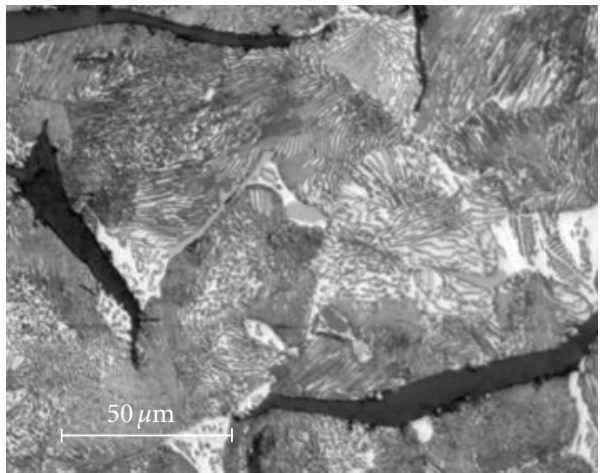

(f)

Figure 2: Morphology of microstructure for Pipes 1-3.

where $R_{p}$ is the polarisation resistance and $\beta_{a}$ and $\beta_{c}$ are anodic and cathodic Tafel constants obtained by taking the slop of the linear part of Tafel plot.

The corrosion rate of the specimens was also calculated by subjecting them to electrochemical frequency modulation (EFM) analysis. The base frequency of $0.1 \mathrm{~Hz}$ was chosen so that waveform repeats after 10 second. Small frequency of 0.2 and $0.5 \mathrm{~Hz}$ was chosen in order to minimise any capacitive behaving influence of double layer [16, 17]. EFM technique has the advantage that corrosion rate of the specimens can be calculated without prior knowledge of Tafel constants. Current density and Tafel components also can be found from frequency spectrum of the current response.

3.3. Identification of Corrosion Products. The nature of corrosion products formed on a limited number of specimens 


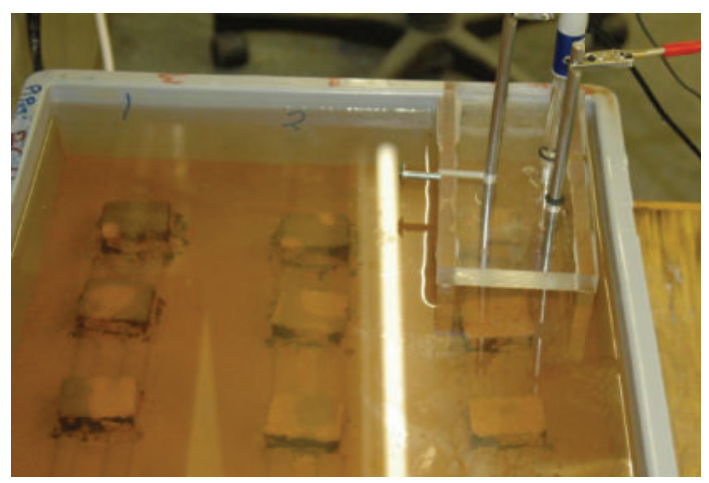

FIgURE 3: Test setup for specimens in test solution.

from Pipes 1-3 was investigated by the means of X-ray photon spectroscopy (XPS) and X-ray diffraction (XRD). The chemical states of the corrosion products were determined by a Thermo, Sigma Probe XPS machine, while the phase status of the corrosion product was investigated by a PANalytical X'Pert Pro XRD. The collected data were then analysed by being referenced to an energy scale with binding energy for a $\mathrm{C} 1 \mathrm{~s}$ spectrum at $284.8 \mathrm{eV}$ and to $\mathrm{Cu} \mathrm{K} \alpha 1$ radiation for XPS and XRD, respectively. For XPS signal processing, the manufacturer software Advantage (v3.75) was used.

Corrosion products formed on the surface of specimens depend on the mechanism of the corrosion, which in turn is a function of environment [14]. Hence, studying the corrosion products can provide useful information regarding the corrosion mechanism as well as the identification of the products formed on the specimens. The XPS (X-ray photon spectroscopy) analysis of the outer- and innermost face of the corrosion product formed on a specimen provides information on the chemical state of the corrosion products, while the XRD information is useful in phase identification of the corrosion products [18].

\section{Test Results and Analysis}

4.1. Morphology of Corrosion Products. Changes in the appearance and colour of the corrosion products formed on the surface of the specimens from all Pipes were examined. Figure 4 summarises the typical changes in the type and state of the corrosion products on specimens from pipe 2 after 0 -, 6-, and 12-month exposure in different environment, that is, Figures 4(a)-4(c) for Static tap water, Figures 4(d)-4(f) for aerated tap water and Figures $4(\mathrm{~g})-4(\mathrm{i})$ for aerated solution of $3.5 \% \mathrm{NaCl}$.

As can be seen from Figure 4, the general appearance of the surface corrosion products was similar for all three pipe materials investigated and was found to vary with exposure type and time. Unsurprisingly, the two exposures involving aerated (flowing) tap water produced the greatest change in the appearance (apparent degree of surface corrosion) in the shortest time (see Figures 4(d)-4(i)). It can also be seen that there was little difference in the general appearance of the corrosion products formed on the surface after a period of six-month exposure (Figures 4(b), 4(e), and 4(h)). After 12month exposure, however, the appearance of the corrosion products formed on the surface of the specimens exposed to the three test environments was observed to be different. That is, the specimens exposed to the aerated solution of $\mathrm{NaCl}$ formed to exfoliated corrosion products as shown in Figure 4(i), whilst the specimens exposed in static water and aerated water have formed an adhering corrosion product (Figures 4(e) and 4(f)). This suggests that the process (and perhaps the rate) of general corrosion on the surface of cast irons can be strongly influenced by the local exposure condition.

These differences in corrosion behaviour were confirmed by the examination of the cut cross-sections of these specimens as shown in Figure 5, where the corrosion products were formed on a specimen from Pipe 2 after 6-month exposure to Figure 5(a) Static tap water, Figure 5(b) Aerated tap water, and Figure 5(c) $3.5 \% \mathrm{NaCl}$ solution. From Figure 5, it can be seen that the corrosion products formed on the specimens exposed to $\mathrm{NaCl}$ solution delaminate from the surface (Figure 5(c)). In contrast, specimens exposed to static and aerated tap water formed an adhering corrosion product, which does not delaminate from the surface (Figures 5(a) and 5(b)). This indicates that the oxide products formed on the surface were influenced by the exposure condition. To better understand the condition of the pipes recovered from the service, the colour of the corrosion products formed on the surface of the specimens during the course of the corrosion has also been studied.

Figures 6 and 7 show the development of the corrosion product that was formed on the surface of specimens from the Pipe 2 exposed to the static and aerated tap water, respectively for different periods of time and in different environments.

For the specimens exposed to static water, an initial layer of adherent, red oxide formed after one month of exposure slowly spread, thickened, and darkened over time and covered the entire surface of the specimens as shown in Figures 6(a)-6(d). Specimens immersed in aerated tap water developed an oxide film of an orange/brown colure (Figure $7(\mathrm{a})$ ), which subsequently changed to orange after 2 months (Figure 7(b)). This oxide layer was seen to be darkened over time as shown in Figures 7(c) and 7(d).

The depth and form of the corrosion developed in the specimens were assessed by metallurgical examination at the cut cross-sections. Figure 8 shows the photomicrographs taken from specimens exposed to aerated tap water after 230 days of the commencement of the test, where Figures 8(a) and 8 (b) are for Pipe 1, Figures $8(\mathrm{c})$ and $8(\mathrm{~d})$ are for Pipe 2, Figures $8(\mathrm{e})$ and $8(\mathrm{f})$ are for Pipe 3 , and the arrow indicates the depth of localised corrosion.

From Figure 8, it can be seen that the general corrosion is minor in all the specimens while localised corrosion seems to be the primary type of degradation. It is also observed that the localised corrosion is more pronounced around carbon-rich phases (graphite flakes) and it is more severe in Pipes 1 and 3 than in Pipe 2. This can be attributed to the differences in the morphology of the graphite flakes and the microstructure of the specimens [19-23]. The result of 

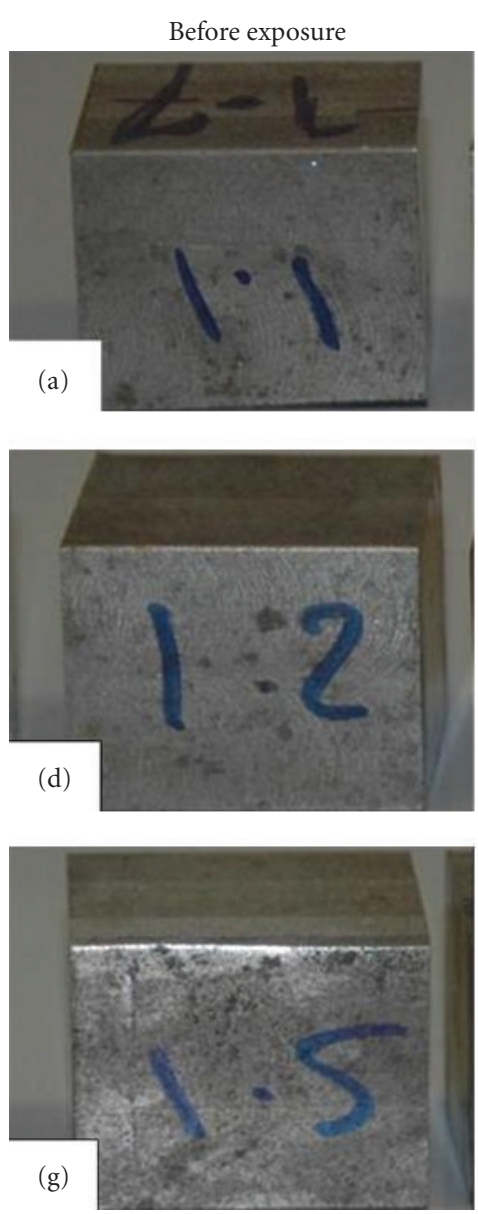
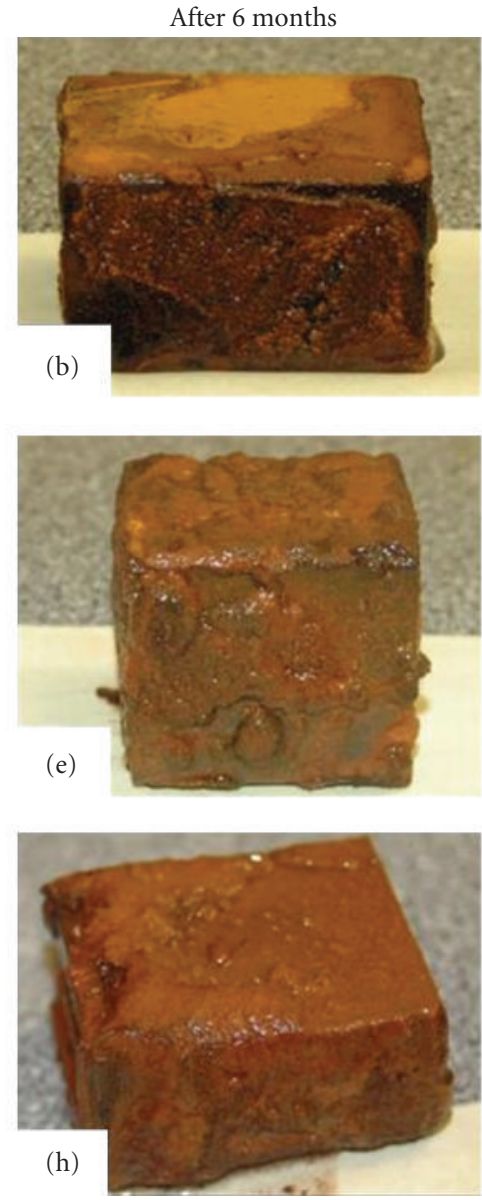
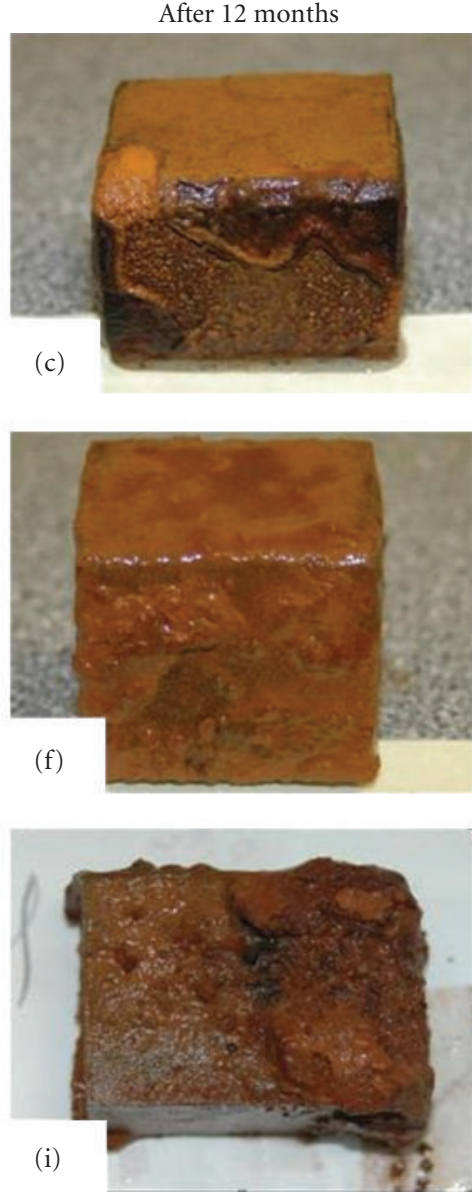

FIgURE 4: Change in the type and state of the corrosion products.

Figure 8 is consistent with the inspection of the postservice pipes in this study which was tabulated in Table 1. It can be seen from the table that plates from Pipe 3, which was previously characterized and identified as mainly pearlitic, experienced more corrosion (corrosion pits) than Pipe 1, which was identified as 50\% pearlitic, and Pipe 2, which was identified as $47 \%$ ferritic (as shown in Table 3 ).

Figure 9 shows the SEM images taken from the corroded zone of specimens from the pipes examined, where Figure $9(\mathrm{a})$ is the graphitization initiating from graphite flakes for Pipe 3 with details in Figures 9(b) and 9(c) is an example of corrosion of pearlite with respect to graphite and eutectic phase for Pipe 1 with details in Figure 9(d). These pictures confirm a relationship between the morphology of the graphite flakes and the extent of the corrosion reaction. From Figure 9(a), it can be noted the corrosion process appears to have initiated from the graphite flakes and is more severe when graphite has a rosette morphology as detailed in Figure 9(b). Where there is no graphite flakes as seen in Figure 9(c), the other phases seem to corrode in the order of their reactivity. That is, from Figure 9 (d), it can be seen that pearlite and ferrite form a galvanic couple with phosphide eutectic and cementite in the microstructure and corrodes in preference. In the presence of the graphite, however, surrounding metal corrode in preference to graphite phase (Figure 9(b)). Literature [20-22] also reported that pearlite and ferrite phases corrode in respect to eutectic and graphite phases. Although ferrite has a good capacity to passivate [23-25], it is reported that it shows a high reactivity and poor ability to passivate when it is coupled with more noble materials in the microstructure [26, 27].

4.2. Corrosion Current and Rate. Results from open circuit potential monitoring of specimens are presented in Figure 10 from which it can be seen that the open circuit potential for specimens of all three pipes in aerated tap water test moves towards more positive potential (less anodic), while in the case of static (anaerobic) experiment, it moves towards less positive (more anodic). For the specimens in 3.5\% $\mathrm{NaCl}$ solution, the potential does not seem to follow a definite trend and it appears to establish around $-700 \mathrm{mV}$. The average corrosion potential in the flowing tap water experiments after one year is $-475,-515$, and $-467 \mathrm{mV}$ for Pipes 1-3, respectively. The fact that Pipe 2 has the lowest potential and Pipe 3 the highest is an indication that the kinetics of the corrosion for Pipe 2 is the lowest and for Pipe 3 is the highest, which can be a result of the microstructural variation of the specimens. That is, the 


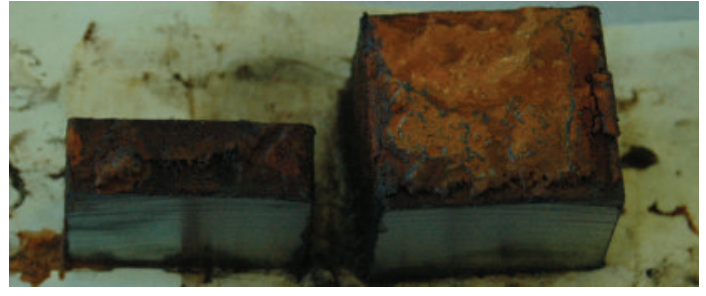

(a)

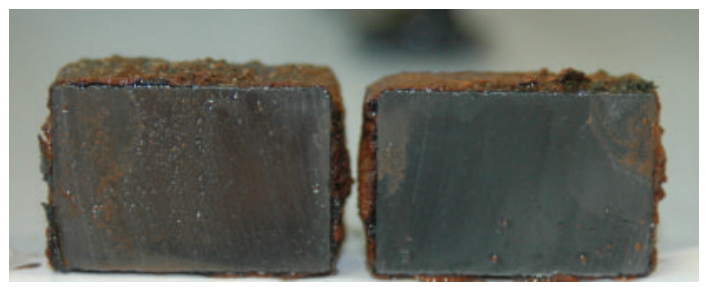

(b)

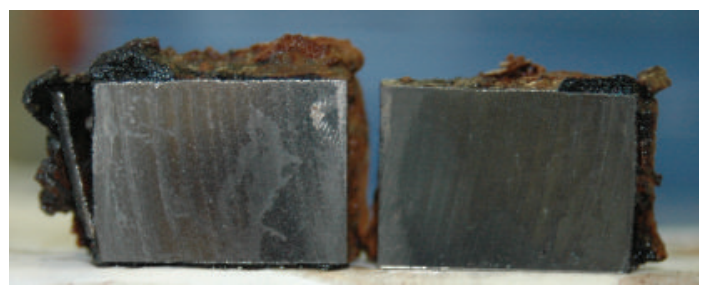

(c)

FIgURE 5: Corrosion products after 6 months after exposure.

corrosion rate of cast iron is expected to be influenced by the volume fraction of the phases of the microstructure [6], among which graphite flake and pearlite are known to be the key phases. For cast iron of the same class, the corrosion rate is expected to increase by an increase in graphite and pearlite volume fraction. Similarly, for solution of $3.5 \% \mathrm{NaCl}$, six months after the commencement of the test, the average corrosion potential for Pipe 2 was measured to be the highest at $-697 \mathrm{mV}$, followed by Pipe 1 at $-691 \mathrm{mV}$ and Pipe 3 at $-687 \mathrm{mV}$, respectively. The same trend is observed for the specimens in static tap water as the average rest potential was measured to be the highest for Pipe 2 at $-693 \mathrm{mV}$, followed by Pipe 1 at $-691 \mathrm{mV}$ and Pipe 3 at $-687 \mathrm{mV}$, respectively. It is also seen that data from Pipe 3 has a wider scatter than those of Pipes 1 and 2.

Figure 11 shows the results of polarisation resistance versus Tafel slops obtained from polarisation scan for the specimens from all pipes in different test solutions. From Figure 11(a), it can be seen that the average polarisation resistance for specimens from Pipe 2 is much higher than that for the other pipes. It can also be seen that Tafel slopes for the specimens exposed to aerated tap water are not consistent and are higher than those reported in the literature $[6,10]$. This suggests that the corrosion rate in aerated tap water perhaps is controlled by diffusion of iron ions through the oxide layer due to the low ion concentration. In the case of the specimens in aerated solution of $3.5 \%$ $\mathrm{NaCl}$ (Figure 11(c)), the presence of chlorine increases the conductivity of the solution and promotes dissolution of iron. Hence, the iron ions concentration in $\mathrm{NaCl}$ solution is higher than in the other experiments, causing the ions to react with the oxygen and drive the corrosion process. Figure 11(c) shows a consistency among the values obtained for Tafel slopes. These values were measured to be in the range of 25-29 and 58-61 mV/decade for anodic and cathodic process, respectively, suggesting that the corrosion process is controlled by cathodic and anodic reactions.

Figure 12 shows the plots of potential versus corrosion current obtained from Tafel scan for the specimens from each pipe in different test solutions. From Figure 12, it can be seen that the specimens of different pipes exposed to the same environment show the similar behaviour in the shape of the curve in spite of the variation in their microstructure and corrosion potential and no distinctive pattern is seen between the plots for different pipes. It can also be seen that a high corrosion rate is expected for the potential greater than $20 \mathrm{mV}$ anodic compared to the rest potential for the electrodes exposed to aerated solution of $3.5 \% \mathrm{NaCl}$. For the specimens exposed to tap water, both aerated and static, the high corrosion rate is expected at much higher potential anodic compared to the corrosion potential.

Table 4 summarises the average rest potential, polarisation resistance, Tafel slopes, and corrosion rate using the DC polarisation technique for the specimens from Pipes 1-3 tested in different solutions. The corrosion rates obtained are consistent and within the range of those reported in the literature [6-9].

From Table 4, not much difference can be seen among corrosion rates of the specimens exposed to different environments, although the specimens exposed to $3.5 \%$ $\mathrm{NaCl}$ are expected to have much higher corrosion rate than specimens exposed to aerated and static tap water, respectively [14]. This can be attributed to the limitation of the DC polarisation technique, which relies on values of Tafel constants for the calculation of corrosion rate. As discussed earlier, these values are higher than those reported in the literature, which suggested that corrosion mechanism is controlled by ion species through the existing oxide layer. The thicker the oxide layer, the more difficult it is for the ions to diffuse in and out. Hence, because of the thick oxide layer formed on the surface of specimens, the corrosion rate calculated by DC polarisation (Tafel) technique can be very misleading.

Table 5 is a summary result of the average Tafel slopes and corrosion rate obtained using electrochemical frequency modulation (EFM) technique for specimens from all pipes in different test solutions. From Table 5, it can be seen that the values of corrosion current and corrosion rate obtained by EFM technique are also in good agreement with $[6,7,9,10]$ except for those in chloride-rich environment. Comparing the corrosion rate obtained by EFM in different test solutions, it can be seen that Pipes 1 and 3 appear to have a higher corrosion rate than Pipe 2, which can be attributable to the differences in the microstructure of these pipes.

4.3. Characterisation of Corrosion Products. Figure 13 shows the spectra of X-ray photon spectroscopy (XPS) for a 


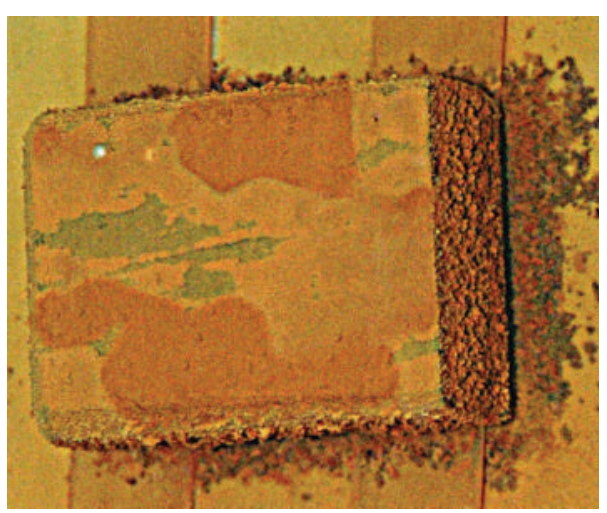

(a)

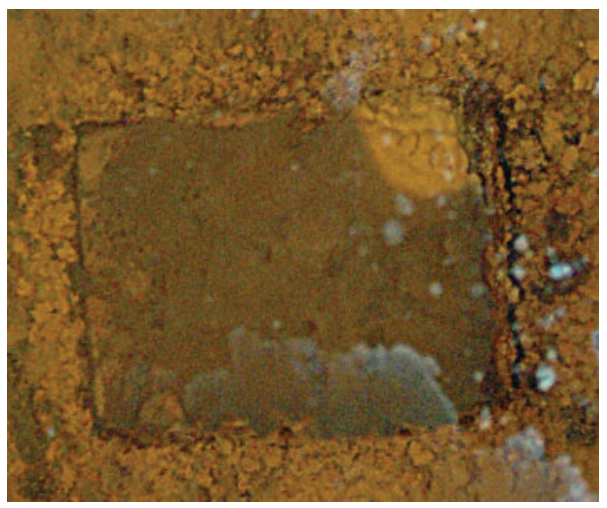

(c)

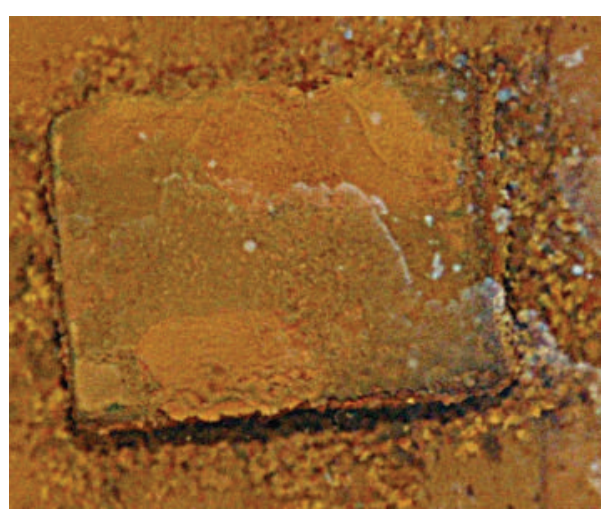

(b)

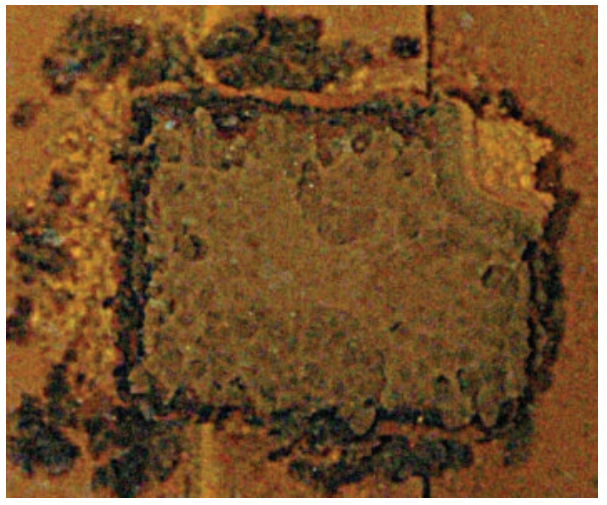

(d)

FIGURE 6: Corrosion products exposed in static tap water after (a) 1 month, (b) 2 months, (c) 5 months, and (d) 12 months.

TABle 4: Potentiostatic parameters and corrosion rate (CR).

\begin{tabular}{|c|c|c|c|c|c|c|}
\hline Solution and time of measurement & Pipe & $E$ & PR (ohms) & $\beta_{a}(\mathrm{mV} /$ decade $)$ & $\beta_{c}(\mathrm{mV} /$ decade $)$ & $\mathrm{CR}(\mathrm{mm} /$ year $)$ \\
\hline \multirow{3}{*}{ Static tap water after one year } & 1 & -0.692 & 85 & 478 & 250 & 0.136 \\
\hline & 2 & -0.695 & 54 & 359 & 221 & 0.146 \\
\hline & 3 & -0.685 & 75 & 402 & 244 & 0.136 \\
\hline \multirow{3}{*}{ Aerated tap water after one year } & 1 & -0.472 & 63 & 230 & 165 & 0.188 \\
\hline & 2 & -0.515 & 142 & 299 & 218 & 0.122 \\
\hline & 3 & -0.467 & 54 & 222 & 164 & 0.195 \\
\hline \multirow{3}{*}{ Aerated solution of $3.5 \% \mathrm{NaCl}$ after six months } & 1 & -0.691 & 10 & 61 & 28 & 0.18 \\
\hline & 2 & -0.697 & 8 & 54 & 29 & 0.152 \\
\hline & 3 & -0.687 & 9 & 59 & 25 & 0.135 \\
\hline
\end{tabular}

specimen from Pipe 2 exposed to aerated tap water after 440 days, where Figure 13(a) is the XPS survey of the outermost surface of the corrosion product, Figure 13(b) is the Fe2p spectrum on inner face, Figure 13(c) is the XPS survey of the innermost surface of the corrosion product, and Figure 13(d) is the Fe2p spectrum on outer face. Figure 13 confirms the presence of $\mathrm{Fe} 2 \mathrm{p}, \mathrm{O} 1 \mathrm{~s}, \mathrm{C} 1 \mathrm{~s}, \mathrm{Cl} 2 \mathrm{p}$, and $\mathrm{Na} 1 \mathrm{~s}$ along with Mn2p3, N1s, and Si2s. These data show that the corrosion products formed on the specimens are primarily the base metal oxide with some carbon. Figures 13(b) and 13(d) reveal the shake-up satellite, a smaller peak accompanied by a larger peak [18] for Fe2p3/2, which is observed to be the same for both the outer and the inner corrosion surfaces and suggests that the corrosion products at the oxide outer surface and the oxide inner surface are the same or very similar. The binding energy of $710.5 \mathrm{eV}$ for Fe2p3/2 is an indication of the oxidized Fe components, and the shake-up satellite is the typical energy pattern for $\mathrm{Fe}_{2} \mathrm{O}_{3}$ iron oxide, which is a stable oxide film and is considered to be insoluble in water $[28,29]$. Any evidence of the existence of $\mathrm{Fe}^{3+}$ ion species in the corrosion products indicates that the corrosion mechanism is controlled by oxygen diffusion through the adhering corrosion product [14].

Figure 14 shows the XPS spectra of a specimen from Pipe 2 exposed to aerated solution of $3.5 \% \mathrm{NaCl}$ after 250 days, where Figure 14(a) is the XPS survey of the 


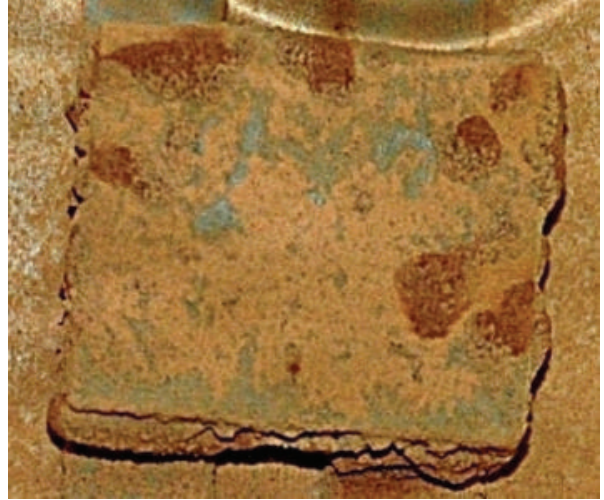

(a)

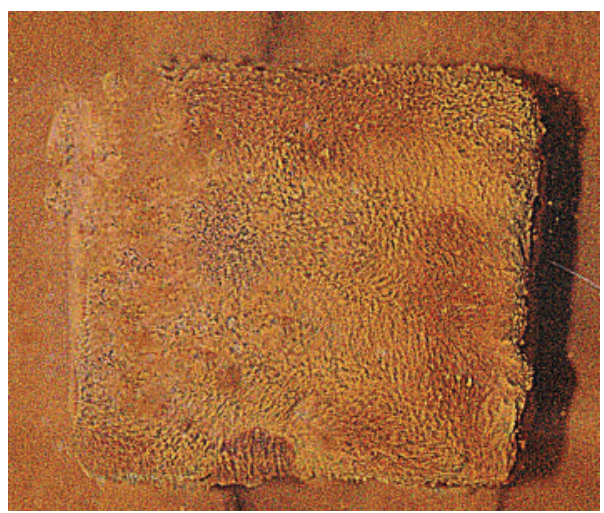

(c)

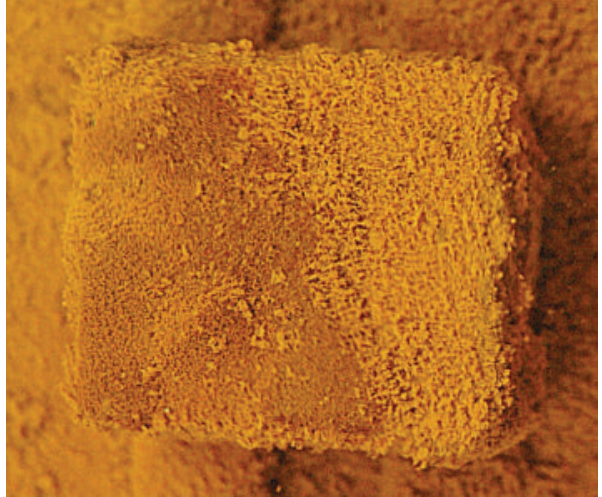

(b)

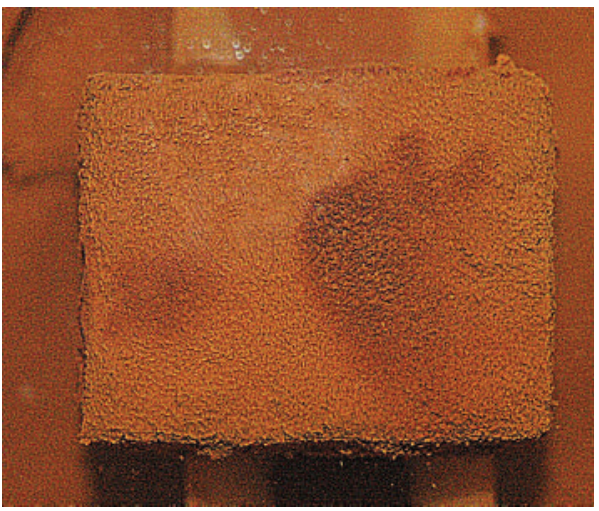

(d)

FIgURE 7: Corrosion products exposed in aerated tap water after (a) 2 months, (b) 3 months, (c) 6 months, and (d) 12 months.

TABLE 5: Tafel slopes and corrosion rate.

\begin{tabular}{lcccc}
\hline $\begin{array}{l}\text { Solution and } \\
\text { time of } \\
\text { measurement }\end{array}$ & Pipe & $\begin{array}{c}\beta_{a} \\
(\mathrm{mV} / \text { decade })\end{array}$ & $\begin{array}{c}\beta_{c} \\
(\mathrm{mV} / \text { decade })\end{array}$ & $\begin{array}{c}\mathrm{CR} \\
(\mathrm{mm} / \text { year })\end{array}$ \\
\hline $\begin{array}{l}\text { Static tap water } \\
\text { after one year }\end{array}$ & 1 & 123.5 & 131 & 0.074 \\
& 3 & 116.9 & 118.85 & 0.12 \\
Aerated tap & 1 & 207.6 & 215.5 & 0.286 \\
water after one & 2 & 223.7 & 233 & 0.239 \\
year & 3 & 179.9 & 187.3 & 0.303 \\
\hline $\begin{array}{l}\text { Aerated solution } \\
\text { of 3.5\% NaCl }\end{array}$ & 1 & 82.4 & 84.5 & 0.69 \\
after six months & 3 & 31 & 31.6 & 0.53 \\
\hline
\end{tabular}

outermost surface of the corrosion product, Figure 14(b) is the Na1s spectra on the outer surface, Figure 14(c) is the XPS survey of the innermost surface of the corrosion product, and Figure $14(\mathrm{~d})$ is the $\mathrm{Cl} 2 \mathrm{p}$ spectra on the inner surface. Figure 14 confirms the presence of chloride ions on the inner face of the corrosion product whereas sodium ions are observed on the outer face.

From Figure 14, it can be seen that the comparatively strong signal of chloride ion from the inner surface of the corrosion product where it is in contact with the metal suggests that this is an anodic face with respect to the outer surface where the intensity of sodium iron signal is larger (Figure 14(c)). The XPS spectrum observed for the binding energy of iron ion of the inner surface of the corrosion product is not a complete shake-up satellite, which suggests that perhaps both $\mathrm{Fe}^{3+}$ and $\mathrm{Fe}^{2+}$ ion species exist in the corrosion product. This is an indication that electrons generated by oxidation of iron can be readily consumed by the oxygen present in the electrolyte solution through the porous conductive corrosion layer as can be shown as follows:

$$
\begin{gathered}
\mathrm{Fe} \longrightarrow \mathrm{Fe}^{2+}+2 \mathrm{e}^{-}, \\
4 \mathrm{Fe}^{2+}+\mathrm{O}_{2} \longrightarrow 4 \mathrm{Fe}^{3+}+2 \mathrm{O}^{2-} .
\end{gathered}
$$

Thus, the corrosion mechanism in $\mathrm{NaCl}$ solution is less dictated by the diffusion of oxygen. The observed difference between the XPS data from the specimens exposed to aerated tap water and aerated solution of $3.5 \% \mathrm{NaCl}$ suggests a different mechanism of corrosion. This has an implication that the corrosion mechanism of the pipes buried underground is a function of the soil type, which can vary from noncorrosive to highly corrosive, as well as surrounding environment, which can also vary in the degree of aeration. 


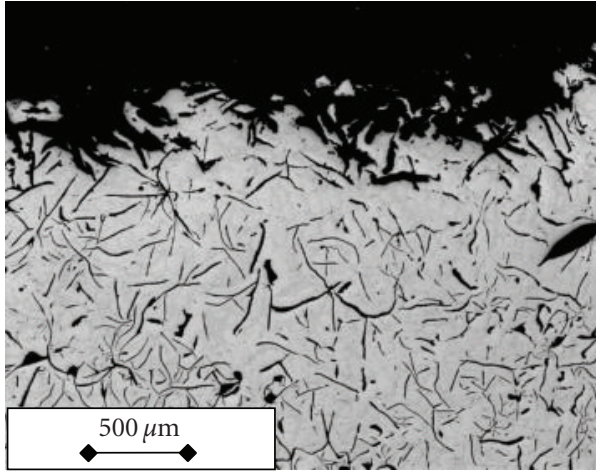

(a)

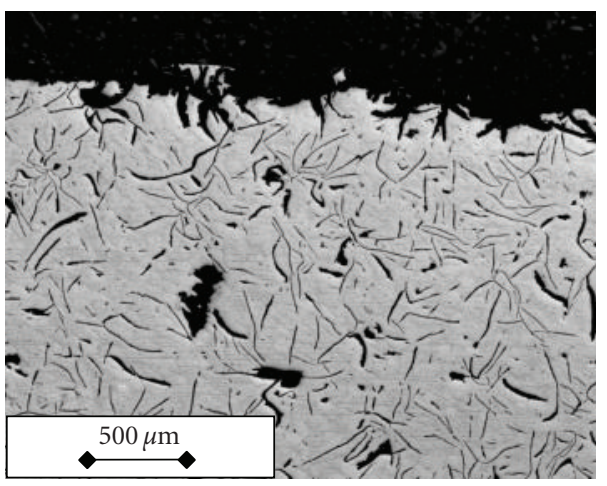

(c)

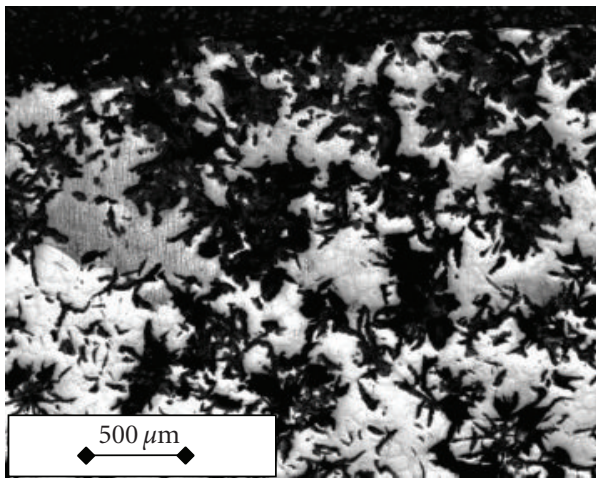

(e)

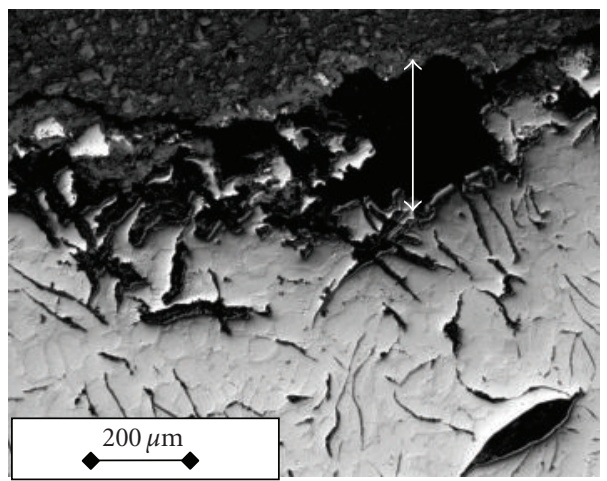

(b)

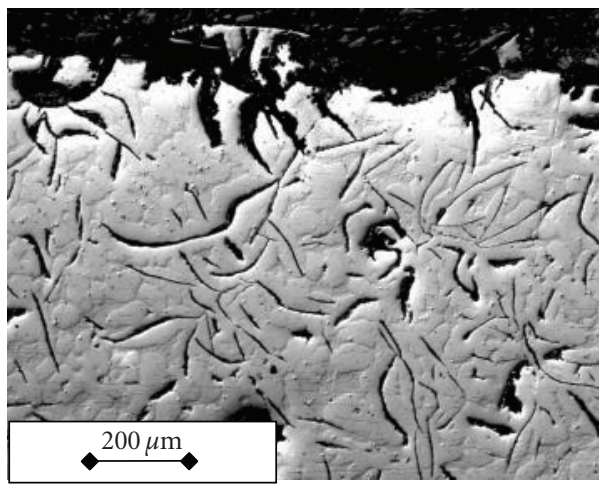

(d)

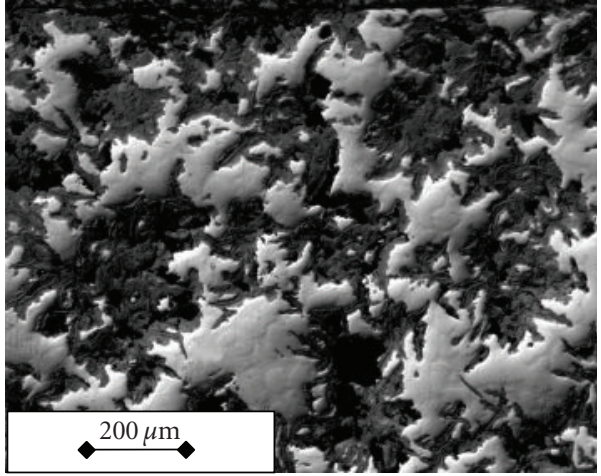

(f)

FIGURE 8: Photomicrophotographs of representative specimens.

Figure 15 shows an example of the recorded X-ray photon spectroscopy (XRD) pattern for the corrosion products formed on a specimen from Pipe 2 after 15-month exposure to the aerated tap water. The XRD patterns recorded for the innermost and outermost corrosion products formed on the specimens from Pipes 1-3 exposed to static tap water, aerated tap water, and $3.5 \% \mathrm{NaCl}$ solution exhibit a very low crystallinity, which makes a quantitative phase analysis impossible.

Figure 16 shows an example of the comparison between the main peak diffracted pattern seen in Figure 15 and the matched library pattern for a specimen from Pipe 2 after 15-month exposure to the aerated tap water. The results of XRD examination suggest that the majority of the phases present are oxides or oxide hydrides of iron. Also, some chlorine-containing phases in the specimens exposed to $\mathrm{NaCl}$ environment and calcium containing phases in specimens exposed to tap water are detected. It should be emphasised that the low crystallinity in the phases present makes a definitive identification unrealistic.

Table 6 shows the iron oxide minerals detected by XRD technique on the outer and innermost corrosion products on the representative specimens from Pipes 1-3, which have been exposed to aerated tap water, static tap water, and 3.5\% $\mathrm{NaCl}$ solution, respectively. From Table 6, it can be seen that the phases in the corrosion products formed on the outer face 


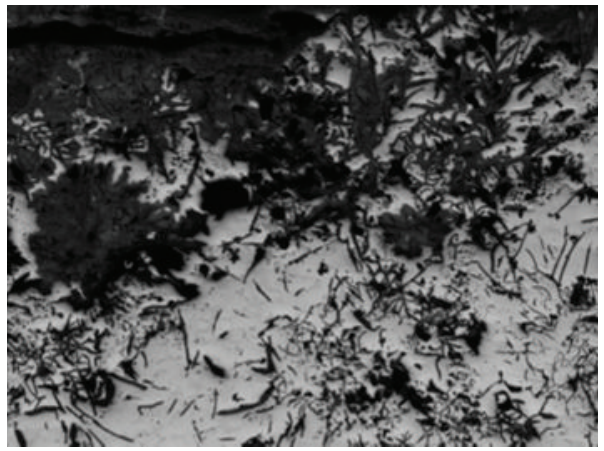

(a)

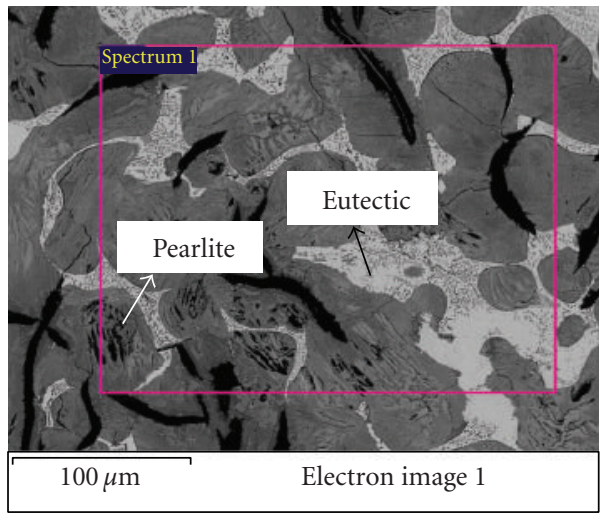

(c)

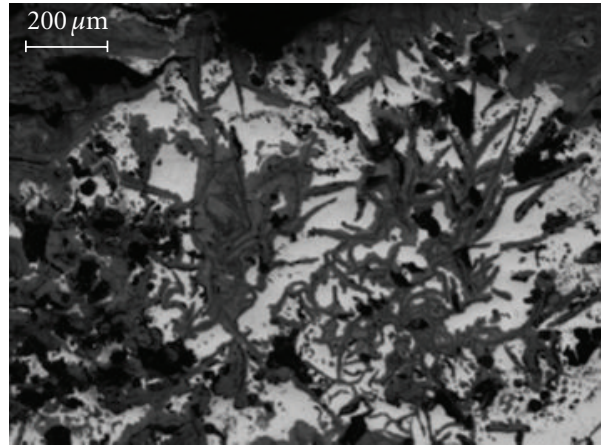

(b)

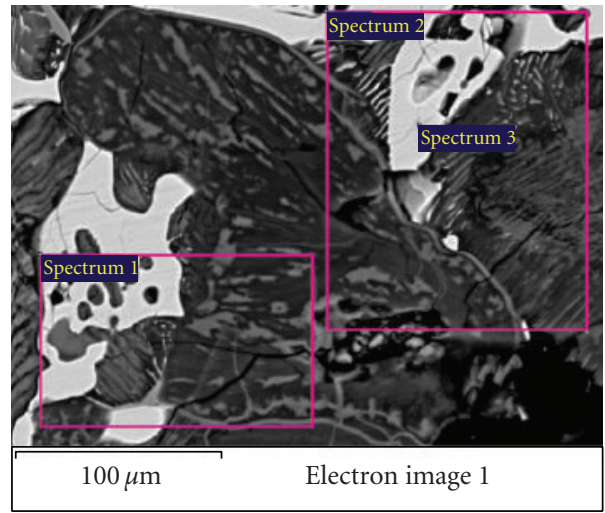

(d)

FIGURE 9: SEM images of corroded zone of exservice pipes.

of all the specimens are very similar. This suggests that the specimens had come to an equilibrium with the environment due to the fact that hydroxyls are the more stable iron species at ambient temperature [30]. The minor differences between them can be the result of different degrees of hydration. On the other hand, the corrosion products formed on the inner face seem to be dictated by the environment and the material. The formation of species such as $\mathrm{Fe}_{3} \mathrm{O}_{4}$ in static tap water as a result of solubility of $\mathrm{Fe}^{2+}$ to $\mathrm{Fe}^{3+}$ and $\mathrm{FeCl}_{3}$ in aerated chlorine-rich environment is generally expected [14]. However, the solubility of $\mathrm{Fe}^{2+}$ and $\mathrm{Fe}^{3+}$ and hence the final corrosion products are reported to be a function of both potential and $\mathrm{pH}[31]$.

\section{Observation and Discussion}

Based on the analysis of the results obtained from a number of techniques that have been employed to study and understand the corrosion behaviour of cast iron pipes, it can be seen that each technique provides a set of useful information that is unique to the method.

It has been seen that localised corrosion is the primary form of corrosion degradation of cast iron water pipes. When considering cast irons of different class, microstructural features such as ferrite, pearlite, and graphite flakes seem to be a key factor in characterising the corrosion rate and properties of cast iron pipes. The intensity of the localised corrosion depends on the extent at which some phases such as pearlite and graphite flake exist in the microstructure. Generally, the corrosion rate for the specimens from ferritic pipes was seen to be slightly lower than that of the pearlitic ones.

The morphology of the corrosion products has implications on the failure analysis of cast iron pipes, and the appearance of the failed surface has implications on the postfailure examination. That is, for understanding whether pipes that failed catastrophically have been leaking for some time before the event, it is crucial to know what the surface would look like after being exposed to the surrounding medium, for example, being washed by the flowing water of the pipe or exposed to moist surrounding soil.

The corrosion behaviour of cast iron pipes in aerated tap water is primarily governed by the active dissolution of iron and absorption of $\mathrm{OH}^{-}$on the ferrous surface. The dissolution rate is expected to increase as the solution becomes more alkaline. Furthermore, in neutral environment the corrosion mechanism appears to be controlled by the diffusion of the ion species, while in alkaline chloride solutions, the corrosion process is controlled by the anodic and cathodic reactions.

For determination of the corrosion rate which depends on the condition of the specimens and the environments (solutions), each technique has a limitation that may cause the results obtained by the technique to be misleading if 
Pipe 1

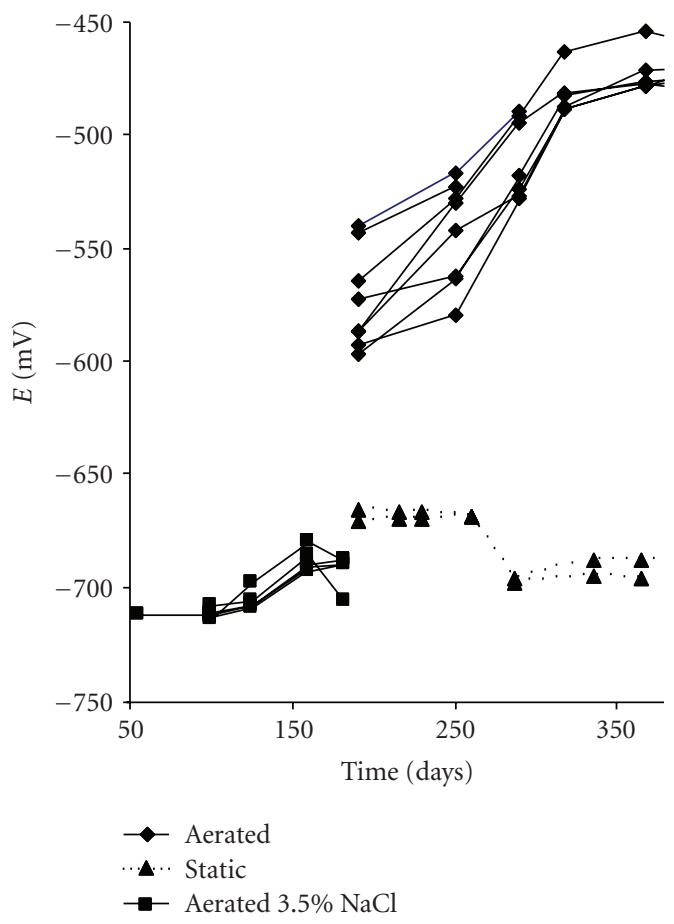

(a)

Pipe 3

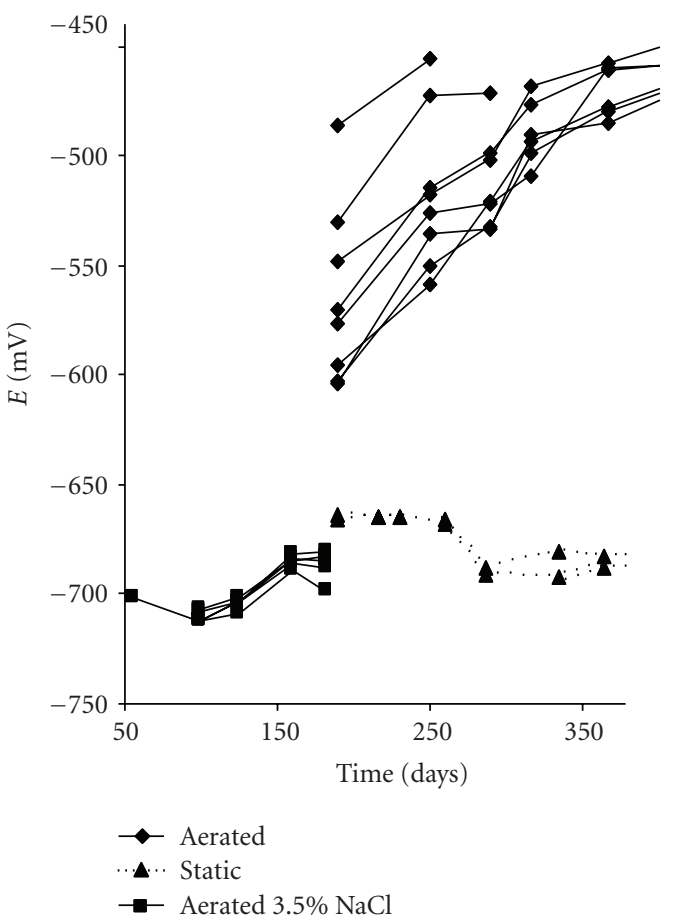

(c)
Pipe 2

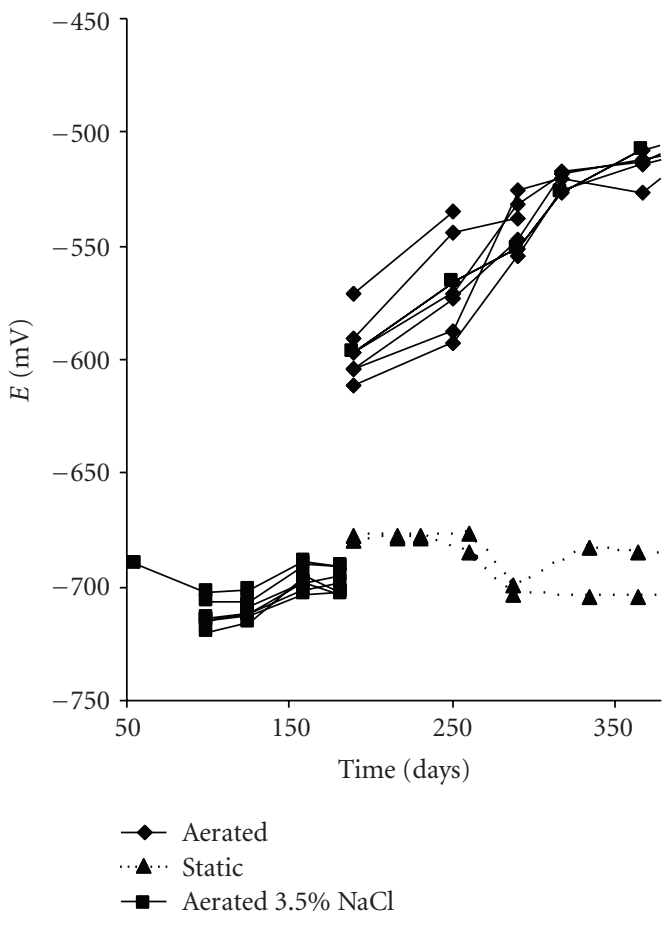

(b)

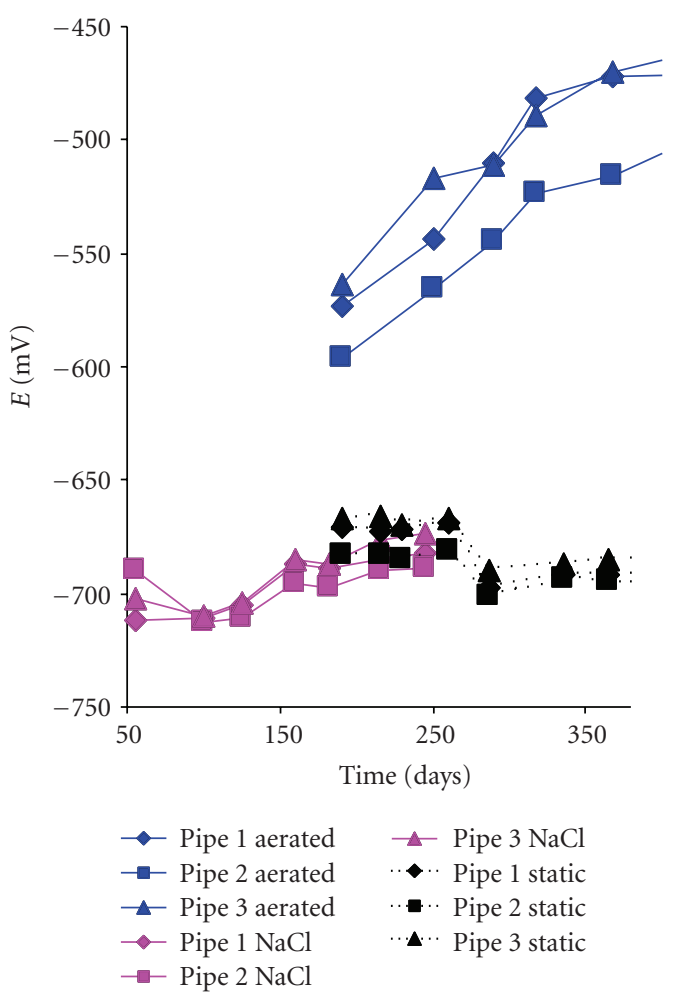

(d)

FIgURE 10: Open circuit potential for Pipes 1-3 in different environment. 

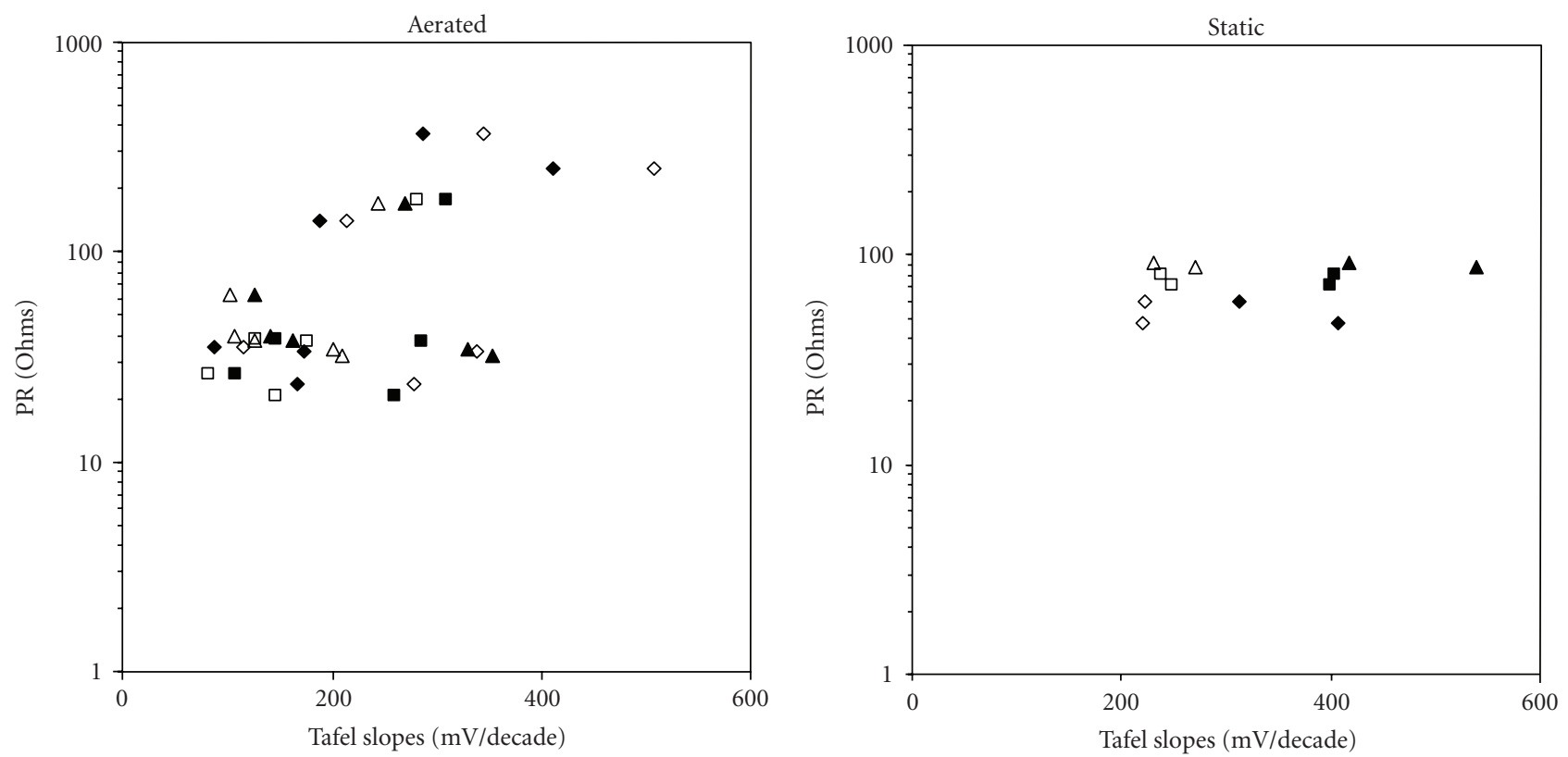
$\Delta$ Pipe 1 anodic
$\triangle$ Pipe 1 cathodic
- Pipe 2 anodic
$\diamond$ Pipe 2 cathodic
- Pipe 3 anodic
$\square$ Pipe 3 cathodic

(a)

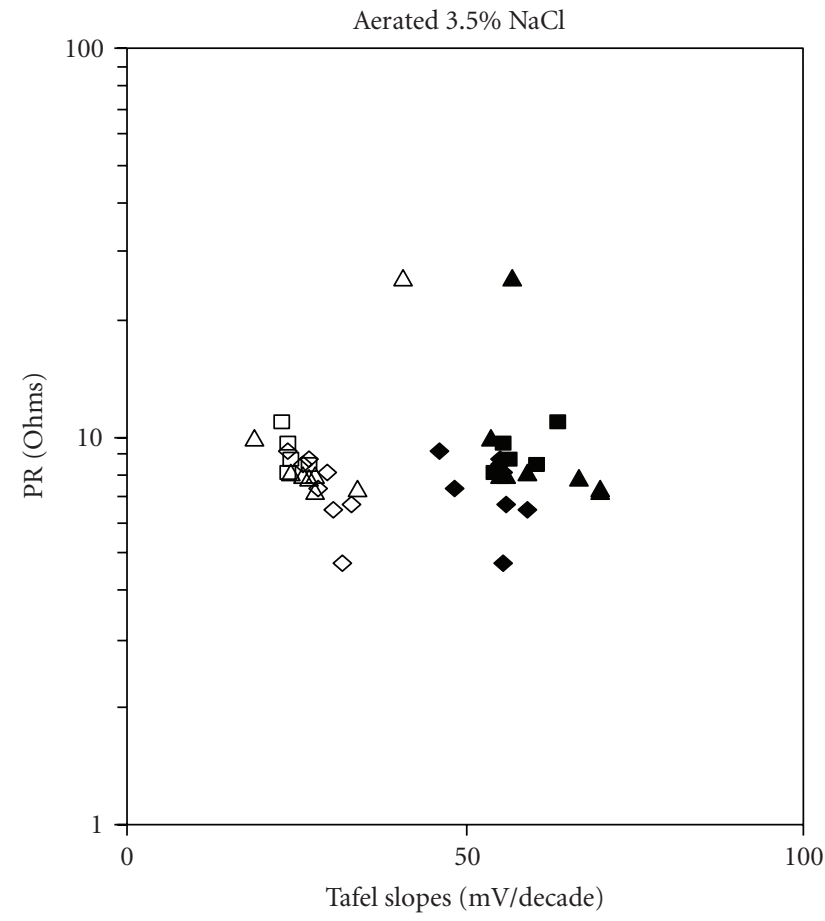

\ Pipe 1 anodic

$\triangle$ Pipe 1 cathodic

- Pipe 2 anodic $\diamond$ Pipe 2 cathodic

- Pipe 3 anodic

$\square$ Pipe 3 cathodic

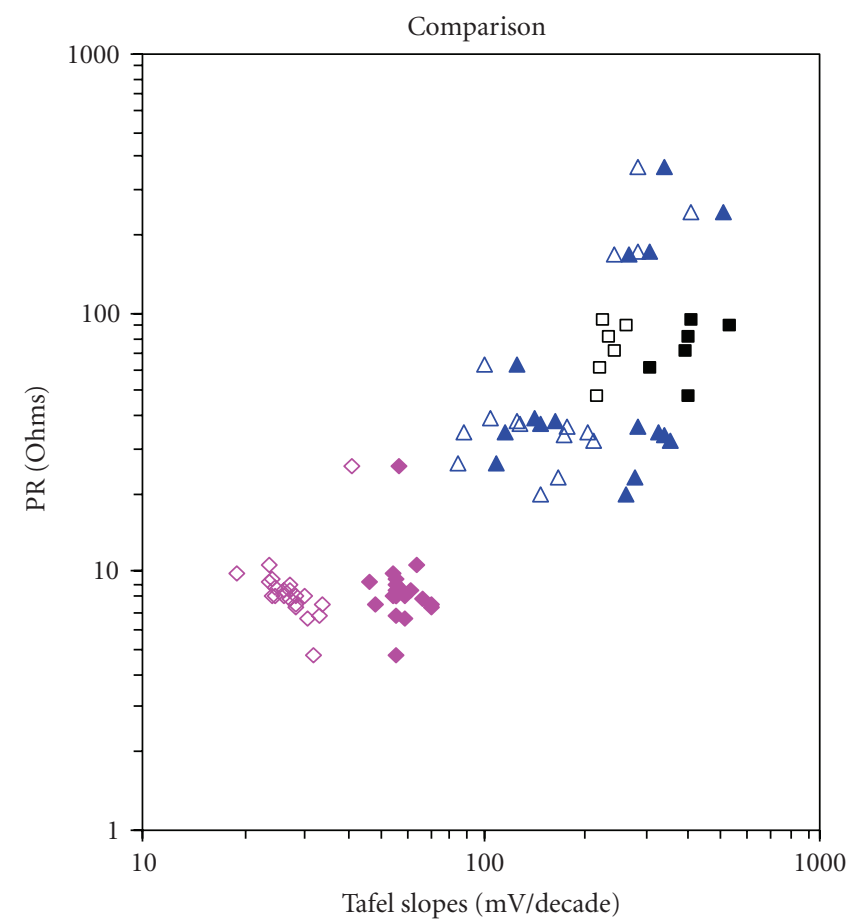

$\triangle$ Pipe 1 anodic $\diamond$ Pipe 2 cathodic

$\triangle$ Pipe 1 cathodic Pipe 3 anodic

- Pipe 2 anodic $\square$ Pipe 3 cathodic

(b)

(c)

$\Delta$ Aerated anodic

$\triangle$ Aerated cathodic

- Static anodic $\square$ Static cathodic

- $3.5 \% \mathrm{NaCl}$ anodic

$\diamond 3.5 \% \mathrm{NaCl}$ cathodic

(d)

FIgure 11: Polarisation resistance versus Tafel slopes. 


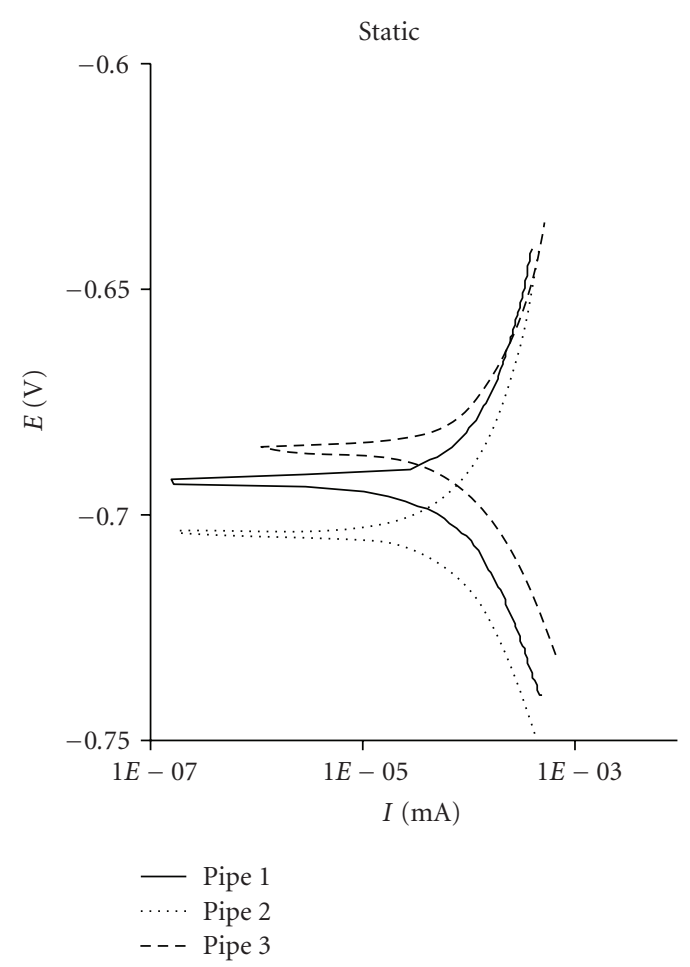

(a)

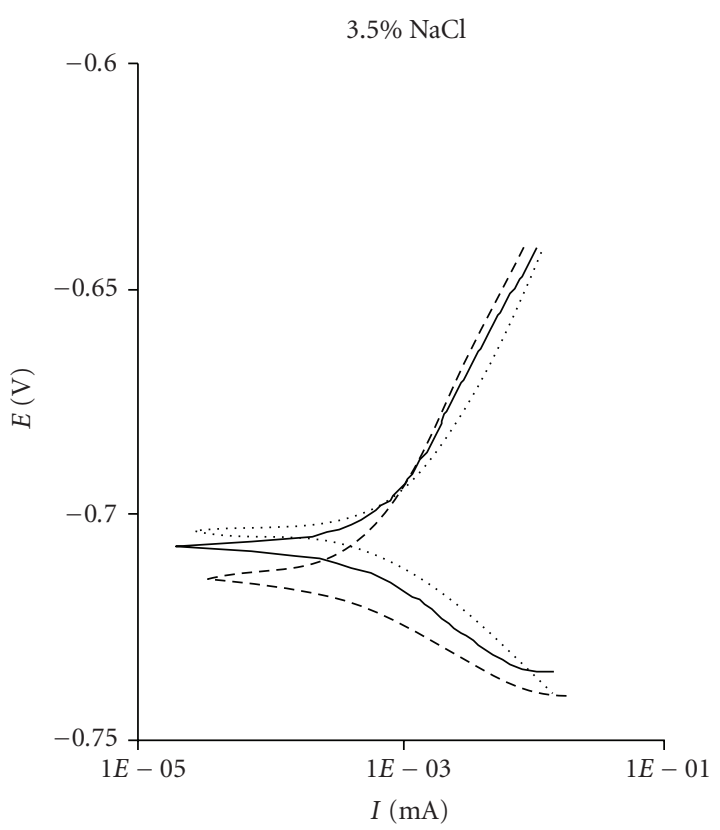

_ Pipe 1
_... Pipe 2
_- - Pipe 3

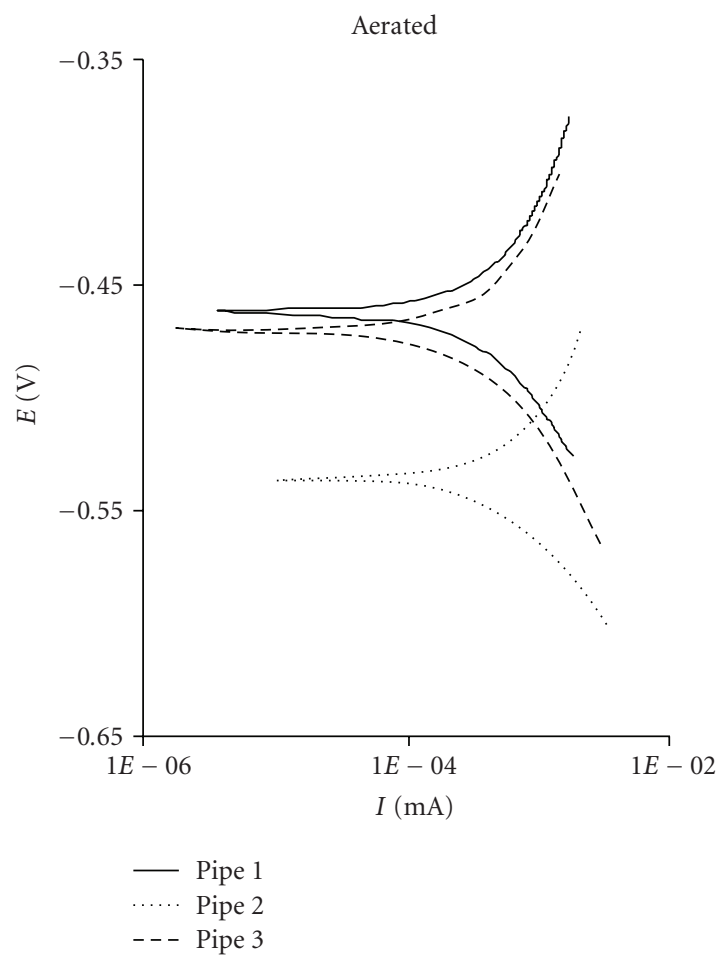

(b)

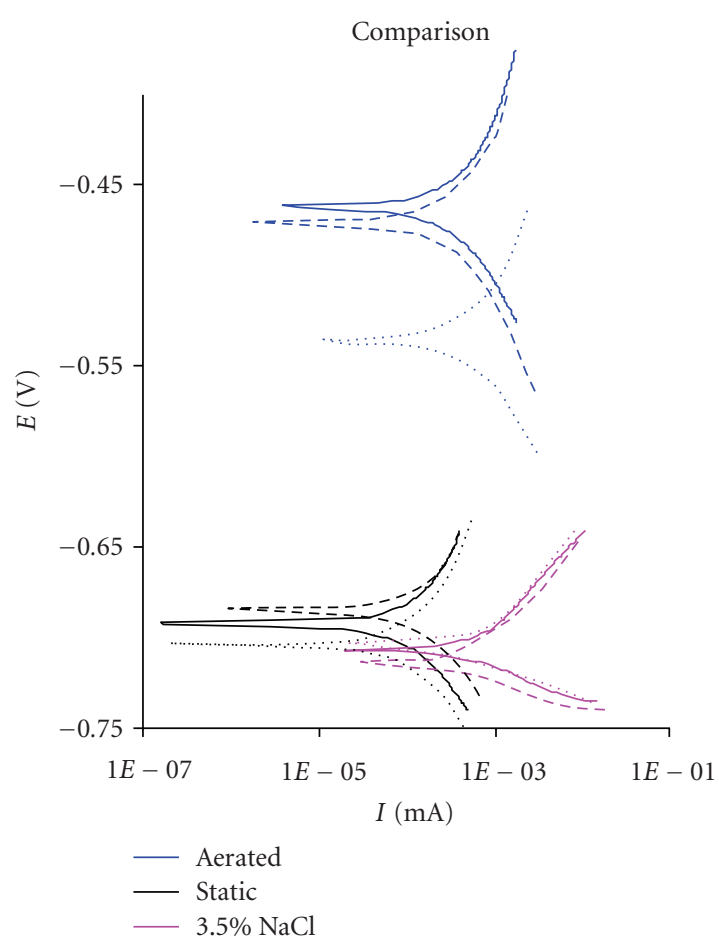

(d)

FIgURE 12: Example of potential polarisation curves.

not interpreted properly. In some cases, the values that are obtained from one method do not account for the actual corrosion behaviour of the specimen. Thus, to be able to obtain a view of true corrosion behaviour, it is useful to employ a number of methods and extract the relevant information from each as conducted in this paper. Therefore the results obtained from a single technique should be regarded as a guide only. For example, the corrosion 


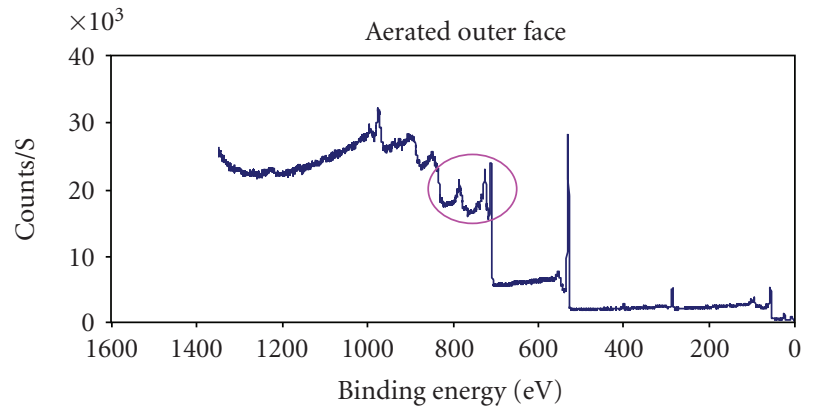

(a)

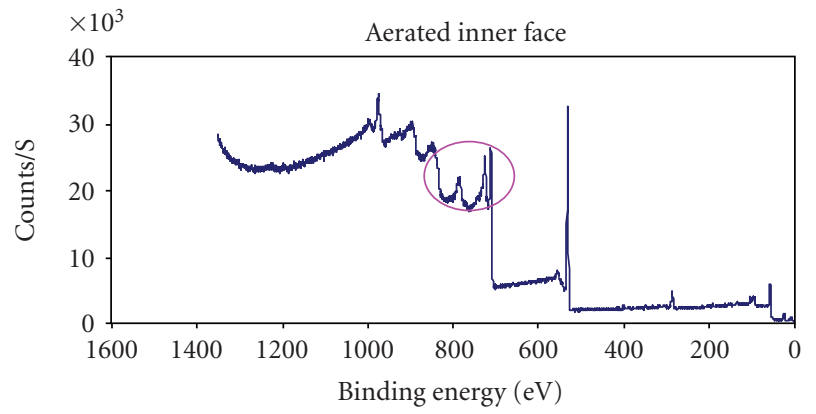

(c)

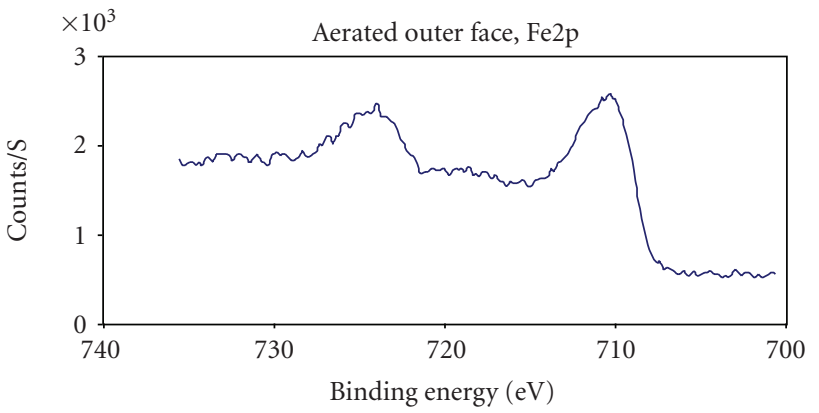

(b)

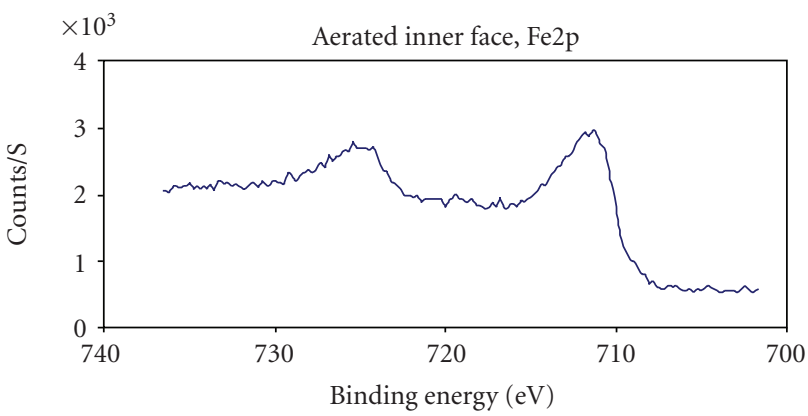

(d)

FIGURE 13: XPS spectra of a specimen exposed to aerated tap water.

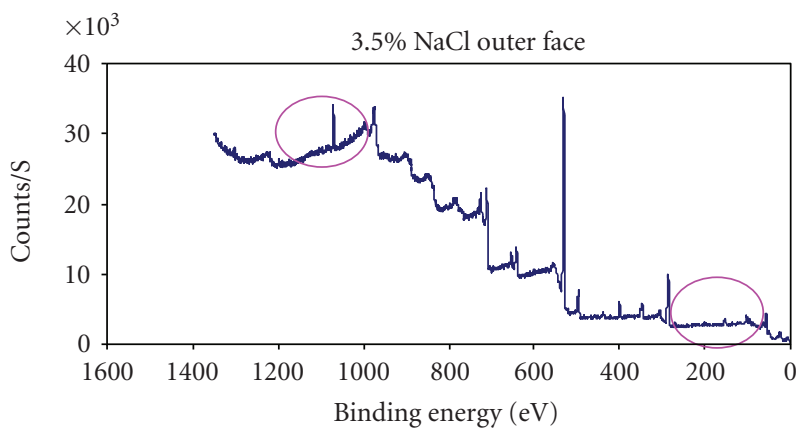

(a)

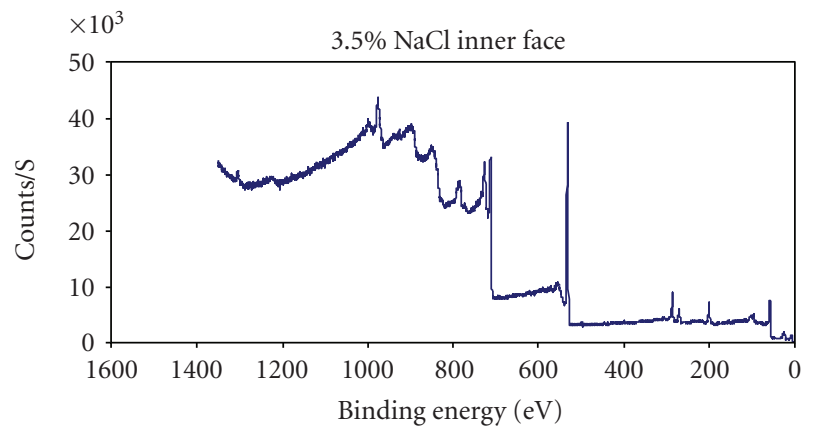

(c)

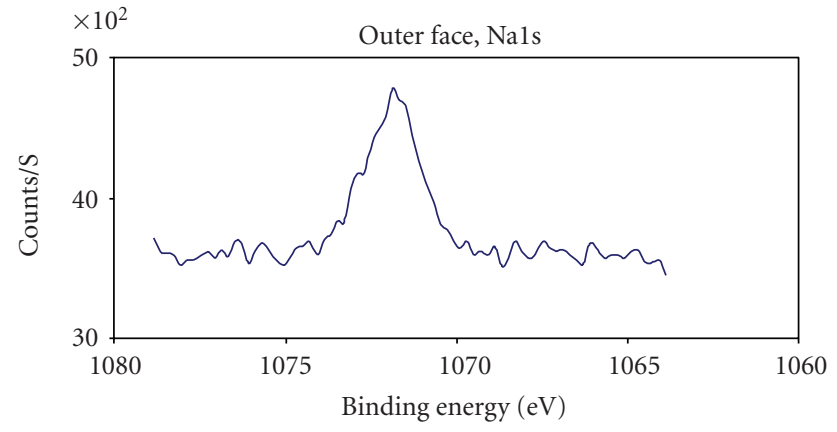

(b)

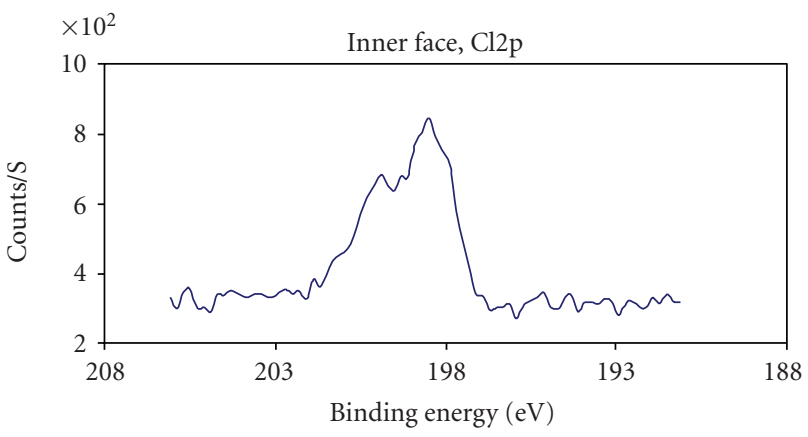

(d)

FIGURE 14: XPS spectra of a specimen exposed in aerated solution of 3.5\% NaCl. 
TABLE 6: Iron oxide minerals detected by XRD.

\begin{tabular}{|c|c|c|c|}
\hline Pipe & Solution & Inner face & Outer face \\
\hline \multirow{3}{*}{1} & Static tap water & $\mathrm{Fe}(\mathrm{OH})_{3}$ & $\mathrm{Fe}^{3+} \mathrm{O}(\mathrm{OH})$ \\
\hline & Aerated tap water & $\mathrm{Fe}^{3+} \mathrm{O}(\mathrm{OH}), \mathrm{Ca}\left(\mathrm{CO}_{3}\right)$ & $\mathrm{Fe}^{3+} \mathrm{O}(\mathrm{OH})$ \\
\hline & Aerated solution of $3.5 \% \mathrm{NaCl}$ & $\mathrm{FeO}(\mathrm{OH})$ & $\mathrm{FeOOH}$ \\
\hline \multirow{3}{*}{2} & Static tap water & $\mathrm{Fe}_{3} \mathrm{O}_{4}, \mathrm{FeO}(\mathrm{OH}), \mathrm{CaO}$ & $\mathrm{Fe}^{3+} \mathrm{O}(\mathrm{OH})$ \\
\hline & Aerated tap water & $\mathrm{Fe}^{3+} \mathrm{O}(\mathrm{OH}), \mathrm{Ca}\left(\mathrm{CO}_{3}\right)$ & $\mathrm{Fe}^{3+} \mathrm{O}(\mathrm{OH}) \mathrm{Ca}\left(\mathrm{CO}_{3}\right)$ \\
\hline & Aerated solution of $3.5 \% \mathrm{NaCl}$ & $\mathrm{FeO}, \mathrm{Fe}^{3+} \mathrm{O}(\mathrm{OH}), \mathrm{Ca}_{3} \mathrm{Fe}_{15} \mathrm{O}_{25}$ & $\mathrm{Fe}(\mathrm{OH})_{3}$ \\
\hline \multirow{3}{*}{3} & Static tap water & $\mathrm{Fe}^{3+} \mathrm{O}(\mathrm{OH}), \mathrm{FeOOH}$ & $\mathrm{Fe}^{3+} \mathrm{O}(\mathrm{OH})$ \\
\hline & Aerated tap water & $\mathrm{FeOOH}, \mathrm{FeCl}_{2}$ & $\mathrm{Fe}^{3+} \mathrm{O}(\mathrm{OH})$ \\
\hline & Aerated solution of $3.5 \% \mathrm{NaCl}$ & $\mathrm{Fe}^{3+} \mathrm{O}(\mathrm{OH}), \mathrm{FeCl}_{3}$ & $\mathrm{Fe}^{3+} \mathrm{O}(\mathrm{OH})$ \\
\hline
\end{tabular}

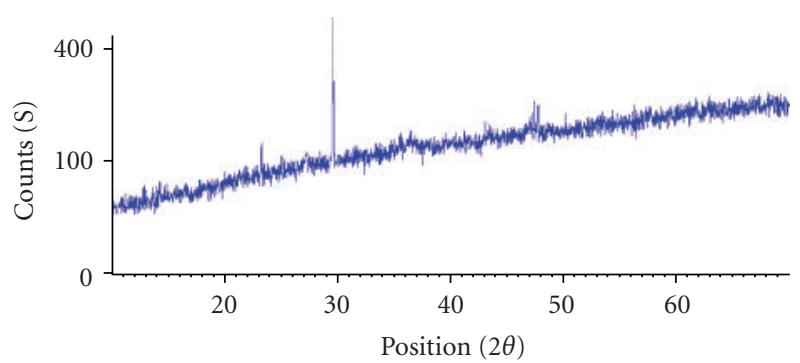

FIGURE 15: XRD from corrosion product of a specimen from Pipe 2.

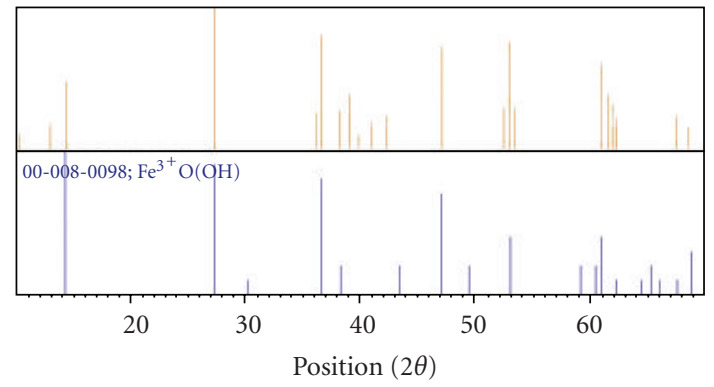

FIGURE 16: XRD peak diffracted pattern seen in Figure 15.

rate obtained by EFM for specimens exposed to 3.5\% $\mathrm{NaCl}$ environment is higher than that obtained by other techniques because EFM technique is more sensitive to changes in the corrosiveness of the environment $[16,17]$. Thus, the reflection of the environment on data obtained using EFM may lead to a higher prediction of corrosion rate. On the other hand, the high values of Tafel slopes obtained for the specimens exposed to aerated tap water suggest that the corrosion rate calculated for the specimens exposed to aerated tap water is underestimated and perhaps is controlled by diffusion of iron ions through the oxide layer due to low ion concentration. Hence, comments on the overall corrosion behaviour of the pipes should be derived from considering the limitation and contribution of each technique.

However, the general corrosion rate obtained by different techniques exhibits similar trends although the actual values of the corrosion rate are different due to the limitations of the measurement techniques used. The values calculated for the corrosion rate of cast iron specimens using DC polarisation need to be viewed with caution. This is because Tafel slopes obtained from Tafel plots do not represent the actual number of electrons exchanged in the reaction due to competing mechanism, such as oxygen diffusion mechanism. It has been observed that the corrosion rate of grey cast iron pipes in aqueous environment can range between $0.1-0.7 \mathrm{~mm}$ /year depending on the oxygen level and the corrosiveness of the environment.

Results from XPS and XRD examination of the corrosion products of the specimens are very useful in that they confirm different corrosion processes and corrosion products for specimens exposed to different environments. For example, XPS results explain the differences observed in corrosion behaviour of the specimens exposed to different test solutions which was obtained during DC polarisation and Tafel experiments. XRD examinations also confirm that when considering the corrosion of cast iron it is important to appreciate that the corrosion behaviour of cast iron pipes is a function of the material of the pipes as well as the physical environment by which the specimens are surrounded.

\section{Conclusion}

Results obtained from a comprehensive experiment on corrosion of three exservice cast iron pipes exposed to three simulated environments have been presented in this paper. Various techniques have been employed to measure the corrosion of cast iron pipes and analyse its behaviour in detail. It has been found that localised corrosion is the primary form of corrosion of cast iron water pipes and that in general corrosion rate obtained by different techniques exhibits similar trends. It has also been found that the microstructure of cast irons appears to be a key factor that affects the corrosion behaviour of cast iron pipes with the corrosion rate for ferritic cast iron pipes slightly lower than that of the pearlitic ones and that the corrosion behaviour of cast iron pipes in aerated tap water is primarily governed by the active dissolution of iron and absorption of $\mathrm{OH}^{-}$on the ferrous surface. It can be concluded that, in the absence of historical data, long-term tests can provide practically useful information on corrosion behaviour of cast iron pipes in a range of service environments. 


\section{Acknowledgments}

Support from Thames Water PLC during the course of this investigation and the Grant from the Engineering and Physical Sciences Research Council (EPSRC), UK with EP/I032150/1 are gratefully acknowledged.

\section{References}

[1] B. Rajani and J. Makar, "A methodology to estimate remaining service life of grey cast iron water mains," Canadian Journal of Civil Engineering, vol. 27, no. 6, pp. 1259-1272, 2000.

[2] K. Atkinson et al., "Failure of small diameter cast iron pipes," Urban Water, vol. 4, no. 3, pp. 263-271, 2002.

[3] K. Yamamoto et al., "Service life prediction of industrial pipeline," Tetsu-To-Hagane/Journal of the Iron and Steel Institute of Japan, vol. 71, no. 1, pp. 121-126, 1985.

[4] P. Marshall, "The residual structural properties of cast iron pipes- structural and design criteria for lining for water mains in pipeline innovation," 2001.

[5] M. Najafi and S. Gokhale, Trenchless Technology Pipeline and Utility Design, Construction, and Renewal, McGraw-Hill, New York, NY, USA, 2005.

[6] R. Mehra and A. Soni, "Cast iron deterioration with time in various aqueous salt solutions," Bulletin of Materials Science, vol. 25, no. 1, pp. 53-58, 2002.

[7] A. E. Krivosheev, B. V. Marinchenko, and N. M. Fetisov, "Corrosion resistance of cast iron with and without additive treatment," Russ Cast Prod, no. 3, pp. 86-87, 1973.

[8] N. R. Smart, D. J. Blackwood, and L. Werme, "Anaerobic corrosion of carbon steel and cast iron in artificial groundwaters: part 2-gas generation," Corrosion, vol. 58, no. 8, pp. 627-637, 2002.

[9] N. R. Smart, D. J. Blackwood, and L. Werme, "Anaerobic corrosion of carbon steel and cast iron in artificial groundwaters: part 1-electrochemical aspects," Corrosion, vol. 58, no. 7, pp. 547-559, 2002.

[10] T. V. Jayaraman et al., "Corrosion studies of single crystals of iron-gallium alloys in aqueous environments," Corrosion Science, vol. 49, no. 10, pp. 4015-4027, 2007.

[11] H. M. S. Belmonte, M. J. Mulheron, and P. A. Smith, "Some observations on the strength and fatigue properties of samples extracted from cast iron water mains," Fatigue and Fracture of Engineering Materials and Structures, vol. 32, no. 11, pp. 916925, 2009.

[12] H. Mohebbi et al., "The fracture and fatigue properties of cast iron used in the water industry," Materials Science and Engineering: A Structural Materials: Properties, Microstructure and Processing, vol. 527, no. 21-22, pp. 5915-5923, 2010.

[13] H. Mohebbi et al., "Characterisation of the fatigue properties of cast irons used in the water industry and the effect on pipe strength and performance," in Proceedings of the 7th International Conference on Modern Practice in Stress and Vibration Analysis, IOP Publishing, Cambridge, UK, September 2009.

[14] L. L. Shreir, R. A. Jarman, and G. T. Burstein, Corrosion, Butterworth Heinemann, Oxford, UK, 3rd edition, 1994.

[15] K. R. Trethewey and J. Chamberlain, Corrosion Science and Engineering, Longman, 2nd edition, 1995.

[16] S. S. Abdel-Rehim, K. F. Khaled, and N. S. Abd-Elshafi, "Electrochemical frequency modulation as a new technique for monitoring corrosion inhibition of iron in acid media by new thiourea derivative," Electrochimica Acta, vol. 51, no. 16, pp. 3269-3277, 2006.

[17] R. W. Bosch et al., "Electrochemical frequency modulation: a new electrochemical technique for online corrosion monitoring," Corrosion, vol. 57, no. 1, pp. 60-70, 2001.

[18] J. F. Watts and J. Wolstenholme, An Introduction to Surface Analysis by XPS and AES, John Wiley \& Sons, New York, NY, USA, 2003.

[19] O. N. Tel'manova, P. P. Karyazin, and V. M. Shtanko, "Behavior of cast-iron with lamellar and globular graphite in dilute acids," Protection of Metals, vol. 16, no. 1, pp. 45-47, 1980.

[20] E. Lunarska, "Effect of graphite shape on the corrosion of grey cast iron in phosphoric acid," Materials and Corrosion, vol. 47, no. 10, pp. 539-544, 1996.

[21] M. Ruscak and T. P. Perng, "Effect of ferrite on corrosion of Fe-Mn-Al alloys in sodium-chloride solution," Corrosion, vol. 51, no. 10, pp. 738-743, 1995.

[22] M. N. Srinivasan and V. Kondic, "Relating microstructure to mechanical properties of flake cast iron," in Proceedings of the International Symposium on the Metallurgy of Cast Iron, Georgi Publishing Company, Geneva, Switzerland, 1975.

[23] S. Al-Hassan et al., "Effect of microstructure on corrosion of steels in aqueous solutions containing carbon dioxide," Corrosion, vol. 54, no. 6, pp. 480-491, 1998.

[24] S. T. Shih, C. Y. Tai, and T. P. Perng, "Corrosion behavior of two-phase $\mathrm{Fe}-\mathrm{Mn}-\mathrm{Al}$ alloys in 3.5-percent $\mathrm{NaCl}$ solution," Corrosion, vol. 49, no. 2, pp. 130-134, 1993.

[25] A. A. Abdul Azim and S. H. Sanad, "Corrosion and corrosion inhibition of C-steel and cast Fe in acid solution," Corrosion Science, vol. 12, no. 4, pp. 337-347, 1972.

[26] F. M. Song et al., "Effect of ferrous ion oxidation on corrosion of active iron under an aerated solution layer," Corrosion, vol. 58, no. 2, pp. 145-154, 2002.

[27] T. Ujiro, K. Yoshioka, and R. W. Staehle, "Differences in corrosion behavior of ferritic and austenitic stainless-steels," Corrosion, vol. 50, no. 12, pp. 953-962, 1994.

[28] V. Arjunan et al., "Electrochemical corrosion behavior of low-carbon I-beam steels in a simulated Yucca Mountain repository environment," Corrosion, vol. 61, no. 4, pp. 381391, 2005.

[29] J. F. Moulder et al., Handbook of X-Ray Photoelectron Spectroscopy, Physical Electronics, Eden Prairie, Minn, USA, 1995.

[30] S. E. Ziemniak, "Metal oxide solubility behavior in high temperature aqueous solutions," Journal of Solution Chemistry, vol. 21, no. 8, pp. 745-760, 1992.

[31] G. L. Makar and D. Tromans, "Pitting corrosion of iron in weakly alkaline chloride solutions," Corrosion Science, vol. 52, no. 4, pp. 250-261, 1995. 

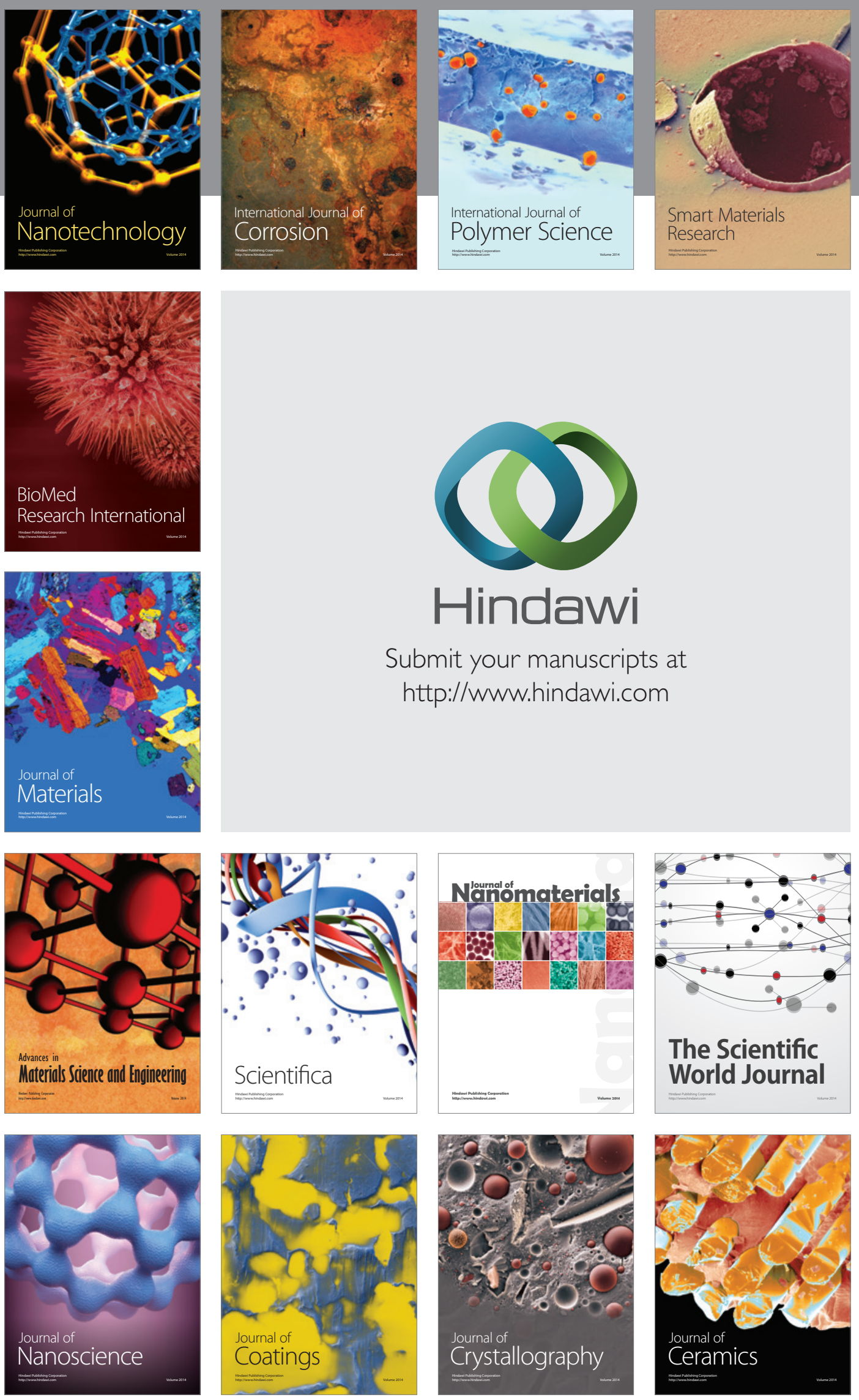

The Scientific World Journal

Submit your manuscripts at

http://www.hindawi.com

\section{World Journal}

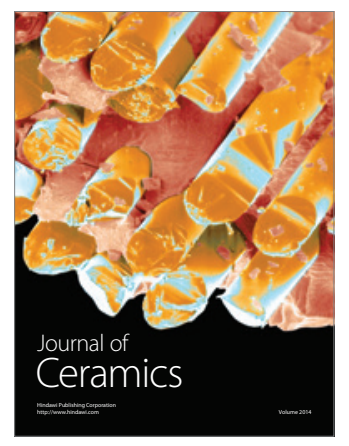

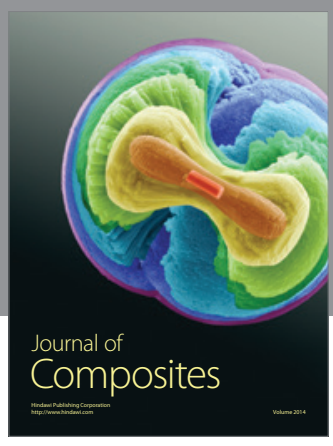
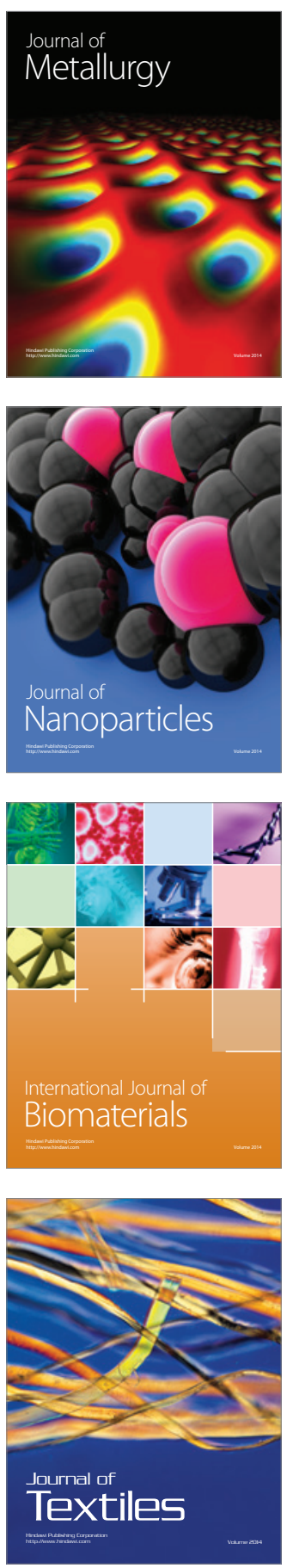